August 1996

\title{
LEARNING IN EVOLUTIONARY ENVIRONMENTS
}

\author{
Giovanni Dosi * \\ Luigi Marengo * \\ Giorgio Fagiolo $^{* * *}$
}

* Dept. of Economics, University of Rome "La Sapienza", Italy and Science Policy

Research Unit (SPRU), University of Sussex, Brighton, UK

Dept. of Economics, University of Trento, Italy

*** Faculty of Statistics, University of Rome "La Sapienza", Italy

Support to this research by the International Institute of Applied System Analysis (IIASA), Laxenburg, Austria; the Italian National Research Council (CNR) and the Italian Ministry of Research ("MURST, Progetti 40\%") is gratefully acknowledged. We benefited from comments on an earlier draft by Daniel Friedman, Yuri Kaniovski, Luigi Orsenigo, the participants to the Schumpeter Society Conference, Stockholm, June 2-5, 1996, and to the lectures by one of us (G.D.) at the Jerusalem Summer School on Mathematical Economics, June 1995; SPRU, University of Sussex, February 1996 ; and at the University of Paris I, May 1996. The usual caveats apply. 


\section{(i) Introduction.}

In the most generic terms, learning may occur in all circumstances whereby agents have an imperfect understanding of the world in which they operate - either due to lack of information about it, or, more fundamentally, to an imprecise knowledge of its structure -; or, when they master only a limited repertoire of actions in order to cope with whatever problem they face - as compared to the set of actions that an omniscient observer would be able to conceive -; or, finally, when they have only a blurred and changing understanding of what their goals and preferences are.

It is straightforward that learning, so defined, is an ubiquitous characteristic of most economic and, generally, social environments, with the remarkable exception of those postulated by the most extreme forms of economic modelling, such as those assuming rational expectations or canonical game-theoretic equilibria. But, even in the latter cases, and neglecting any issue of empirical realism of the underlying assumptions -, it is natural to ask how did agents learn in the first place about e.g. the "true model" of the world in a RE set-up, or the extensive form of a particular game? And, moreover, in the widespread case of multiple equilibria, how do agents select among them (i.e. how do they learn how to converge to one of them)?

Of course, learning acquires even greater importance in explicitly evolutionary environments (which we believe be indeed the general case), where a) heterogeneous agents systematically display various forms of "bounded rationality"; b) there is a persistent appearance of novelties, both as exogenous shocks, and, more important, as the result of technological, behavioural and organisational innovations by the agents themselves; c) markets (and other interaction arrangements) perform as selection mechanisms; d) aggregate regularities are primarily emergent properties stemming from out-of-equilibrium interactions (more detailed discussions are in Dosi and Nelson (1994), Nelson (1995), Coriat and Dosi (1995b)).

The purpose of this work is to present a sort of selective guide to an enormous and diverse literature on learning processes in economics in so far as they capture at least some of the foregoing evolutionary aspects. Clearly, this cannot be a thorough survey. Rather, we shall just refer to some examples of each genre, trying to show their links and differences, setting them against a sort of ideal framework of "what one would like to understand about learning...". This allows also an easier mapping of a wide and largely unexplored research agenda. A significant emphasis shall be put on learning models, in their bare-bone formal structure, but we shall always refer to the (generally richer) non-formal theorising about the same objects. 
Needless to say, we are exclusively concerned here with positive (i.e. descriptive) theories of learning: standard "rational-choice" models might well go a longer way as normative tools.

In section (ii) we set the scene for the discussion that follows by reference to the usual decision-theoretic archetype, briefly outlining many compelling reasons why one needs to go well beyond it in order to account for most learning processes. Once we do that, however, a sharp and unified - albeit probably irrelevant - paradigm is lost. Learning happens in different cognitive and behavioural domains, has different objects and most likely occurs through somewhat different processes. Relatedly, we propose that a few basic empirical regularities on cognition, decision-making and learning stemming from disciplines outside economics - ranging from cognitive psychology to sociology, etc. - should be among the "building blocks" of an emerging theory of agency (cf. section (iii)). Some taxonomic exercises are a useful introductory device. These we shall present in section (iv). A taxonomy of learning dynamics, and the restrictions on its domain, helps so in grouping and assessing various classes of learning models (cf. section (iv)). In particular, a useful distinction appears to be whether one retains some elements of Savage's original "Small World assumption" (Savage (1954)) - in essence, the idea of a finite list of objects exhaustively present from the start in the "heads" of learning agents-. This is the case of learning representations through "evolutionary games" and other mechanisms of adaptation via environmental reinforcement. Conversely, lower restrictions on the domain of learning and on the dimensionality of the state space may well entail open ended evolutionary dynamics involving not only adaptation but also discovery and emergence of novelty: in section (v), we shall compare different formal approaches in these different veins.

The general thrust of the argument, there and throughout this work, shall be that learning crucially entails cognitive activities of construction and modification of mental models and behavioural patterns hardly reducible to well defined problems of choice under imperfect information and probabilisable risk.

Some achievements and limitations of current learning models within this perspective and a few other broad topics of investigation such as the relationship between learning and selection in evolutionary models; the possible tension between individual and collective learning; the specificity of organisational learning, shall be outlined in section (vi). 


\section{(ii) Beyond "rational choice" and Bayesian learning: some preliminaries.}

As well known, the standard decision-theoretic model depicts agency (and, in primis, economic agency) as a problem of choice where rational actors select, among a set of alternative courses of action, the one which will produce (in expectation) the maximum outcome as measured against some utility yardstick. In that, agents are postulated to know the entire set of possible events of "nature", all possible actions which are open to them, and all notional outcomes of the mapping between actions and events (or at least come to know them after some learning process). Clearly, these are quite demanding assumptions on knowledge embodied into or accessible to the agents - which hardly apply to complex and changing environments. In fact, they cannot apply almost by definition in all environments where innovations of some kind are allowed to occur - irrespective of whether they relate to technologies, behavioural repertoires or organisational arrangements: as Kenneth Arrow has been reminding for some time, if an innovation is truly an innovation it could not have been into the set of events that all agents were able to contemplate before the innovation actually occurred...

Moreover, equally demanding are the implicit assumptions concerning the procedural rationality involved in the decision process.

As a paradigmatic illustration, take the usual decision-theoretic sequence leading from 1) representation/"understanding" of the environment (conditional on whatever available "information"), to 2) evaluation/judgement; 3) choice; 4) actions, and, ultimately, 5) consequences - determined e.g. by the stochastic pairing of actions and "events of nature" and/or actions by other agents.

We argue at some greater length elsewhere (Dosi et al. (1994)) that in order for this "rationalist" view to hold at least two assumptions are crucial.

First, the linearity of that sequence must strictly hold. That is, one must rule out the possibility of reversing, so to speak, the procedural sequence. For example, one cannot have preferences and representations which adapt to an action that has already been undertaken. and, likewise, one must assume that consequences do not influence preferences (i.e. preferences are not endogenous).

Second, at each step of the process agents must be endowed with, or able to build, the appropriate algorithm in order to tackle the task at hand - being it representing the environment, evaluating alternatives or choosing courses of action, etc.

There are, indeed, a few rather compelling reasons why these assumptions might be a misleading starting point for any positive theory of learning and choice. 


\section{Complexity and procedural rationality.}

On purely theoretical grounds, computability theory provides some sort of dividing line between problems which are solvable by means of a general recursive procedures in non-exponential times and problems that are not (for discussions and some results cf. Lewis (1985a) and (1985b), Casti (1992), Andersen (1994), Dosi and Egidi (1991), Dosi et al. (1994)). It is plausible to use such a criteria to establish the upper bound of the complexity of the problems for which the theory is allowed to assume that the agents "naturally" possess the appropriate problem-solving algorithm (or are able to access them in finite time). It happens, however, that many decision tasks within and outside the economic domain fall outside of this category (Lewis (1986), Dosi et al. (1994)).

We do not mean to overemphasise this point. After all, human agents tackle every day, with varying degrees of success, highly complex and "hard" problems (in the sense of computability theory). However, we do claim that the understanding of how and when they happen to do it is a major challenge for any theory of cognition and learning, which cannot be written out by assuming that agents embody from the start a notionally unbounded procedural rationality ${ }^{1}$. Note that all this equally applies to the "procedural rationality" of both decision-processes and of learning. "Rationality" of the latter implies the availability of some inferential machinery able to extract the "correct" information from environmental signals (Bayes rule being one of them, and possibly also the most demanding in terms of what the agents must know from the start about alternative hypotheses on what the world "really is"). But, again, our foregoing argument implies that such an inferential machinery cannot be innocently postulated. Indeed, outside the rather special domain of "small worlds" whose structure is known ex ante to the agents, a few impossibility theorems from computation theory tell us that a generic inferential procedure does not and cannot exit (More on this point in Dosi and Egidi (1991), Dosi et al. (1994), Binmore (1990)).

What said so far mainly implies restrictions on the applicability of the canonical "rational" account of learning and decision-making. The bottom line is that the demands it

\footnotetext{
${ }^{1}$ In this respect, the reader might notice that the view suggested here tends to imply a somewhat more radical departure from fully "rational" theories of decision than Herbert Simon's path-breaking works on "bounded rationality" Simon ((1976), (1981) and (1988)), in that it does not only demand demands a constructive theory of the procedures themselves by which agents develop their representations and action rules, but it allows the possibility of persistently incoherent procedures (see below).
} 
makes in terms of a priori knowledge of the environment and "algorithmic endowments" of the agents cannot be met, even in principle, except for the simplest decision problems.

But, then, how do we theoretically depict agency and learning?

\section{“As...if” interpretations of rational behaviour.}

One possible strategy basically involves a continuing commitment to "rational" micro-foundations of economic interactions, together with a radical redefinition of the status of rationality assumptions themselves.

"Rationality" - however defined -, rather than being an approximation to the empirical behaviours of purposeful, cognitively quite sophisticated, agents, is assumed to be, so to speak, an "objective" property of behaviours in equilibrium. Add the presumption that (most) observed behaviours are indeed equilibrium ones. And finally postulate some dynamics of individual adaptation or intra-population selection leading there. What one gets is some version of the famous "as...if" hypothesis, suggested by Milton Friedman (1953) and rejuvenated in different fashions by more recent efforts to formalise learning/adaptation processes whose outcome is precisely the "rationality" assumed from the start (archetypical examples of this faith can be found in Sargent (1993) and Marimon (1995)).

A thorough, critical, discussion of the "as...if" epistemology has been put forward by Sidney Winter, in various essays (e.g. Winter (1971)) to which we refer the interested reader (and see also Silverberg (1988), Andersen (1994) and Hodgson (1988)).

For our purposes here let us just note the following:

(i) Any "as...if" hypothesis on rationality, taken seriously, is bound to involve quite a few restrictions similar to those briefly overviewed earlier with reference to more "constructive" notions of rational behaviours, simply transposed into a more "ecological" dimension - being it the "ecology" of minds, ideas, organisations, populations, etc. -. That is, canonical rationality, stricto sensu, postulates that one decides and acts by purposefully using the appropriate procedures (or by learning them in purposeful, procedurally coherent, ways). "As...if"”'s of any kind apparently relax the demands on what agents must consciously know about the environment, their goals, the process of achieving them, but at the same time must assume some background mechanism that generates the available alternatives which must include the "correct" ones. However, without any further knowledge of the specific mechanisms, such a possibility remains a very dubious shortcut. 
And it is utterly unlikely when there are infinite alternatives which ought to be scanned.

(ii) While "realistic" interpretations of rationality put most of the burden of explanation upon the power of inbuilt cognition, "as...if" accounts shift it to selection dynamics - no matter whether driven by behavioural reinforcements alike salivating Pavlovian dogs, or by differential reproduction of traits within populations. ${ }^{2}$ But, then, supporters of the view ought to show, at the very least, robust convergence properties of some empirically justifiable selection dynamics. As it stands, in our view, nothing like that is in sight. On the contrary, except for very special set-ups, negative results are abundant in e.g. evolutionary games or other forms of decentralised interactions - no matter whether applied to biology or economics -: path-dependency cannot easily be disposed of; cyclical limit behaviours might occur (cf. Posch (1994) and Kaniovski et al. (1996)), etc. And all this appears even before accounting for environments which are genuinely evolutionary in the sense that novelties can emerge over time.

Of course, the "as...if" theoretical enterprise in its wildest formulation does not set to itself any falsification challenge. Any kind of observation-based discipline on behavioural assumptions tends to be contemptuously dismissed as "ad-hoc". Thus, the question of "what do people do and how do they learn" is generally transformed into another one, namely "given whatever behaviour, and, knowing that, of course (?!), such a behaviour is an equilibrium one, how can I - the theorist - rationalise it as the outcome of some adaptive process? (Mr. Pangloss, theologians, and marxist-leninists would not have any query with such an exercise...).

\footnotetext{
${ }^{2}$ Incidentally note that the outcomes of pure "Pavlovian" - i.e. reinforcement - driven, consciously blind -, and "Bayesian" - apparently sophisticated rational - dynamics can be shown to be sometimes asymptotically equivalent (the review in Suppes ((1995a) and (1995b)) develops much older intuitions from behaviourist psychology - e.g. Bush and Mosteller (1955))... However, in order for that equivalence to hold reinforcements must operate in the same direction as the Bayesian inferential machinery - which is indeed a hard demand to make. The so-called condition of "weak monotonicity" in the dynamics of adjustment that one generally finds in evolutionary games is a necessary, albeit not sufficient, condition to this effect. Moreover, a subtle question regards the interpretative value that one should attribute to asymptotic results: what do they tell us about finite time properties of empirical observations? (We shall briefly come back to the issue below).
} 


\section{Bounded Rationality.}

Another major perspective maintains that cognitive and behavioural assumptions have to keep some empirical foundations and, thus, when needed, account for constraints on memory, on the maximum levels of complexity of problem-solving algorithms, and on computational time. It is, in a broad sense, the bounded rationality approach, pioneered by the works of Simon (cf. (1986)) and developed in quite different fashions in e.g. organisational studies (starting from March and Simon (1958) and Cyert and March (1963)) ; evolutionary theories (building on Nelson and Winter (1982); see also Dosi et al. (1988), Andersen (1994), Hodgson (1993)) ; “evolutionary games” (for a rather technical overview, cf. Weibull (1995); for insightful remarks on bounded rationality and games in general, Kreps (1996) and also in otherwise quite orthodox macroeconomics see e.g. Sargent $\left.(1993)^{3}\right)$. Again, this is not the place to undertake any review of this vast literature. However, few comments are required.

Of course, the very idea of "bounds" on rationality implies that, at least in finite time, agents so represented fall short of full substantively rational behaviours, the latter involving among other things, a) a full knowledge of all possible contingencies ; b) an exhaustive exploration of the entire decision tree; and c) a correct appreciation of the utility evaluations of all mappings between actions, events and outcomes (Simon (1986) and (1988)).

Given that, a first issue concerns the characterisation of the origins and nature of the "boundedness" itself. It is not at all irrelevant whether it relates mainly to limitations on the memory that agents carry over from the past, or to algorithmic complexity, or to limited ability of defining preferences over (expected) outcomes...

Or, more radically, couldn't it be due to the fact that agents get it basically wrong (in terms of representation of the environment, etc.) ?

Here the theory faces a subtle but crucial crossroads. An alternative - unfortunately found too often in economic models, and especially but not only, in game theory - is to select the bounded-rationality assumptions with extreme casualness, suspiciously well-fitted to the mathematics the author knows and to the results one wants to obtain. We have no problem in associating ourselves to those who denounce the ad-hocry of the procedure. The other alternative entails the acknowledgement of an empirical discipline upon the restrictions one puts upon the purported rationality of the agents. No doubt, we want to

${ }^{3}$ Note, however, that in some interpretations - including Sargent's and others discussed in section (iv) below - boundedly rational behaviours are considered mainly in so far as they entail convergence to 
advocate here the scientific soundness of this procedure, notwithstanding the inevitable "phenomenological" diversity of cognitive and behavioural representations one is likely to get. That is, whether and how "rationality is bound" is likely to depend on the nature of the decision problem at hand, the content in which the decision-maker is placed, the pre-existing learning skills of the agents, etc. Taxonomical exercises are inevitable, with their seemingly clumsy reputation. But, in a metaphor inspired by Keith Pavitt, this is a bit like the comparison of Greek to modern chemistry. The former, based on the symmetry of just four elements, was very elegant, grounded in underlying philosophical principles, utterly irrelevant, and, from what we know nowadays, essentially wrong. The latter is clumsy, taxonomic, and for a long time (until quantum mechanics) lacking underlying foundations , but is certainly descriptively and operationally more robust....

A second major issue, regards procedural rationality. Granted the bounds on "substantive" rational agency, as defined above, when and to what extent should one maintain any assumption of coherent purposefulness and logical algorithmic consistency of the agents ? ${ }^{4}$ In a first approximation, H. Simon's approach suggests such a theoretical commitment (associated indeed to major contributions to the identification of constructive procedures for learning and problem-solving in this vein ; cf. Newell and Simon (1972) and Simon (1976)). However, even procedural consistency might not be at all a generic property of empirical agents (including, of course, us !). And a lot of evidence from most social disciplines seems to point in this direction (see also below).

Third, and relatedly, the very notion of "bounded rationality" commits from the start to an implicit idea that "full rationality" is the underlying yardstick for comparison. In turn, this implies the possibility of identifying some metrics upon which "boundedness" and, dynamically, learning efforts could be measured and assessed. In quite a few circumstances this can be fruitfully done ${ }^{5}$ but in others it might not be possible either in practice or even in principle. In particular, this applies to search and learning in complex functional spaces (as

some pre-defined equilibrium outcomes. Hence they turn out at the end being primarily instrumental building blocks of some dynamics vindicating, in the intentions of the proponents, an "as...if" story. ${ }^{4}$ Note that procedural rationality requires all the "linearity assumptions" mentioned above (ruling out for example state-dependent preferences) and also consistent search heuristics (allowing, for example, assessment rules along any decision tree which at least in probability lead in the "right" direction).

${ }^{5}$ Promising results stem from a better understanding of the formal structure of problem-solving heuristics (c.f. e.g. Pearl (1984), Vassilakis (1995) and, in a suggestive experimentally-based instance, Cohen and Bacdayan (1994) and Egidi (1996)). See also below. 
many problems within and outside the economic arena commonly do) ${ }^{6}$. And of course this is also the case of most problems involving discovery and/or adaptation to novelty.

Since indeed these features are typical of evolutionary environments, an implication is that one might need to go well beyond a restricted notion of "bounded rationality", simply characterised as an imperfect approximation to a supposedly "full" one - which, in these circumstances, one is even unable to define what it should precisely be.

But then, again, how does one represent learning agents in these circumstances?

\section{(iii) "Stylised facts" from cognitive and social sciences as building blocks of evolutionary theories of learning.}

Our somewhat radical suggestion is that evolutionary theories ought to make a much greater and systematic use of the evidence from other cognitive and social sciences as sort of "building blocks" for the hypotheses on cognition, learning and behaviours that one adopts. We fully realise that such a perspective almost inevitably entails the abandonment of any invariant axiomatics of decision and choice. But, to paraphrase R. Thaler (1992) this boils down again to the alternative between being "vaguely right" or "precisely wrong": we certainly advocate the former (however, compare Marimon (1995) for a sophisticated contrary view).

In this respect, the discussion of routines as foundational behavioural assumptions of evolutionary models in Nelson and Winter (1982) is an excellent example of the methodology we have in mind, unfortunately not pursued enough in subsequent evolutionary studies (For a discussion of the state-of-the-art in the field, see Cohen et al. (1995)).

There are, however, many other fields where a positive theory of learning in economics can draw, ranging from cognitive and social psychology all the way to anthropology and sociology of knowledge.

\section{Cognitive categories and problem-solving.}

A crucial aspect of learning regards most often cognition, that is the process by which decision makers form and modify representations in order to make some sense of a reality

\footnotetext{
${ }^{6}$ For example, in Dosi et al. (1994) we consider quantity- and price-setting as cases to the point.
} 
which is generally too complex and uncertain to be fully understood. Hence, the necessity to acknowledge the existence (and persistence) of a systematic gap between the agents cognitive abilities and "reality" (were there an omniscient observer able to fully grasp it). Such a gap can take at least, two often interrelated forms ${ }^{7}$, namely, first, knowledge gap, involving incomplete, fuzzy or simply wrong representations of the environment and, second, a problem-solving gap between the complexity of the tasks agents face and their capabilities on accomplishing them.

Regarding both, evolutionary theories of learning might significantly benefit from that branch of cognitive studies concerned with the nature and changes of categories and mental models (in different perspectives, cf. Johnson-Laird (1983) and (1993), Lakoff (1987), Holland et al. (1986), Margolis (1987), and the presentation of a few alternative theories in Mayer (1992)). It is crucial to notice that, if one accepts any "mental model" view, learning cannot be reduced to information-acquisition (possibly cum Bayesian processing of it), but rather is centred around the construction of new cognitive categories and "models of the world" (Few studies in economics have explicitly taking this road: one of them is the promising attempt in Tordjman (1996) to interpret the dynamics of financial markets in this framework; see also Marengo and Tordjman (1996) and Palmer et al. (1984)).

In turn, a robust evidence shows that cognitive categories are no clear-cut constructions with sharp boundaries and put together in fully consistent interpretative models. Rather, they seem to display (in all our minds !) blurred contours, shaded by an intrinsic fuzziness, held around some cognitively guiding "prototypes", and organised together in ill-structured systems kept operational also via a lot of default hierarchies (cf. on all those points Lakoff (1987), Holland et al. (1986), Tversky and Kahneman (1982), Kahneman and Tversky (1986), Griffin and Tversky (1992), Marengo (1996), Margolis (1987), Marengo and Tordjman (1996), Einhorn and Hogarth (1985)). ${ }^{8}$

\footnotetext{
${ }^{7}$ Heiner (1983) introduces a similar concept which he calls the "C-D (competence - difficulty) gap". In his definition such a gap reflects the agent's imperfect capabilities to correctly process the available information and act reliably. Heiner's C-D gap does not properly belong to the realm of cognitive gaps, but it rather capture their behavioural consequences.

8" Prototypization" is easy to intuitively understand: you would give a sparrow rather than a penguin as an example of what a bird is... But with that it is also easier to understand the basic ambiguity of boarderliners, fuzziness and categorical attributions by default (how should one treat a duck-billed platypus?, as a mammal? or should one create a separate category, that of ovoviviparous?...). A discussion of these issues bearing on economic judgements and behaviours is in Tordjman (1996).
} 


\section{Framing and social embeddedness.}

Cognitive categories - it has been repeatedly shown - go together with various mechanisms of framing by which information is interpreted and also rendered operationally meaningful to the decision-makers (cf. Kahneman et al. (1982), Borcherding et al. (1990), March (1994)).

Frames appear to be indeed an ubiquitous feature of both decision-making and learning. What one understands is filtered by the cognitive categories that one holds and the repertoires of elicited problem-solving skills depend on the ways the problem itself is framed. That is, framing effects occurs along all stages of the decision process - affecting representations, judgements and the selection of behaviours (cf. Kahneman et al (1982), and, concerning the patterns of activation of experts' skills, Ericsson and Smith (1991)).

As James March put it,

Decisions are framed by beliefs that define the problem to be addressed, the information that must be collected, and the dimensions that must be evaluated. Decision makers adopt paradigms to tell themselves what perspective to take on a problem, what questions should be asked, and what technologies should be used to ask the questions. Such frames focus attention and simplify analysis. They direct attention to different options and different preferences. A decision will be made in one way if it is framed as a problem of maintaining profits and in a different way if it is framed as a problem of maintaining market share. A situation will lead to different decisions if it is seen as being about "the value of innovation" rather than "the importance of not losing face" (March (1994), p. 14).

Note that in this view, "frames" include a set of (non-necessarily consistent) beliefs over "what the problem is" and the goals that should be achieved in that case ; cognitive categories deemed to be appropriate to the problem; and a related menu of behavioural repertoires.

Moreover, framing mechanisms appear at different levels of cognitive and behavioural observation: they do so in rather elementary acts of judgement and choice, but are also a general organising principle of social experience and collective interactions (Bateson (1972), Goffman (1974)). 
One can intuitively appreciate also the links between framing processes and social embeddedness of both cognition and action ${ }^{9}$.

Frames - in the broad definition given above - have long been recognised in the sociological and anthropological literature (whatever name is used to refer to them) as being grounded in the collective experience of the actors and in the history of the institutions in which agency is nested ${ }^{10}$.

Indeed, embeddedness seems to go a striking long way and affect even the understanding and use of cognitively basic categories such as that of causality and the very processes by which humans undertake basic operations such as inferences, generalisations, deductions, etc. (Lakoff (1987), Luria (1976)).

\section{Heuristics in judgement and learning.}

We were mentioning above the issue of procedural coherence in decision-making and learning (which, to repeat, is a quite separate one from the sophistication in terms of memory and computing power - of the procedures themselves). It happens that an overwhelming evidence points at the widespread use by empirical agents of heuristics which may well lead to systematic biases in judgements and action-choices as compared to the predictions of "rational" decision theoretic models (cf. Kahneman, Slovic and Tversky (1982) and also Kahneman and Tversky (1986), Slovic et al. (1989), Borcherding et al. (1990), Thaler (1992), Shafir and Tversky (1992)).

Broadly defined, heuristics are methods, rules or criteria guiding e.g. representation, judgement or action - and include simple rules-of-thumb but also much more sophisticated methods explicitly evoking the use of mental categories -.

It is impossible to provide here any thorough account of the findings in this area (The classic reference is the cited Kahneman, Slovic and Tversky (1982)). Let us just recall heuristics such as representativeness (i.e. evaluating whatever observation in terms of distance from some prototype or modal case) ${ }^{11}$; availability (i.e. ... what is primarily in

\footnotetext{
90n the notion of "social embeddedness" as from contemporary economic sociology, see Granovetter (1985) and several contributions in Smelser and Swedberg (1994). A discussion quite germane to the argument developed here is in Tordjman (1996).

${ }^{10}$ Within an enormous literature, just think of a good deal of the sociological tradition influenced by the works of Talcott Parson or of the classic Bourdieu (1977); in anthropology, among others, cf. the discussions of "embeddedness" by Karl Polanyi ((1944) and (1957); and Geertz (1963); see also Edgerton (1985)).

${ }^{11}$ Tordjman (1996) discusses in this light speculative expectations.
} 
your mind is what is in your sight...); and anchoring (initial conditions, either related to the way the problem is posed or the experience of the agent influence the final judgement). Other observed phenomena - touching, together, representations, choices and the perceived utility of the latter - include status quo biases (entailing, for choice under risk, risk-aversion for gains and risk-seeking for losses - as formalised by Kahneman and Tversky through "prospect theory" -); overconfidence and illusion of control (associated with the overestimation of one's own capabilities and the neglect potentially relevant outside information ${ }^{12}$; and, more generally systematic "incoherence" vis-à-vis any canonical model of utility-based decision under uncertainty).

Note that all these cognitive and behavioural regularities apply to both decisions (as taken once-and-for-all) and learning processes (for example, representativeness heuristics lead to learning patterns at odds with Bayesian predictions ; and illusion of control is likely to entail information-censuring and escalating commitments in the face of unfavourable outcomes...).

It is straightforward that those cognitive and behavioural patterns openly conflict with "procedural rationality" - which, as mentioned earlier, is a fundamental necessary condition for a standard decision-theoretic account of agency.

It is also remarkable that the foregoing evidence is drawn to a considerable extent for experiments that are simple enough to provide a corresponding "correct" decision-theoretic answer (i.e. procedurally coherent, making the best use of the available information and in accordance to some supposedly basic preference axioms) ${ }^{13}$. And in fact, a lot of the emphasis has been put upon the biases that all this entails, as measured against the canonical normative yardstick. However, together with such (indeed crucial) exercises of empirical falsification, our impression is that not enough has been done in terms development of alternative theories of cognition and action (Kahneman-Tversky's "prospect theory" being one of the few exceptions in a wider puzzle...). More than that: it might well be that socalled "biases" emerging in relatively simple decision set-ups could be revealing clues about cognition and behaviours in all other genuinely evolutionary circumstances which are

\footnotetext{
${ }^{12}$ Cf. Kahneman and Lovallo (1993) and Dosi and Lovallo (1995).

${ }^{13}$ Incidentally, an issue that is seldom raised, and that unfortunately we shall not be able to discuss here either, is whether the "rationality" of decision and learning is assessed procedurally at each elicited step of the process or whether it is black-boxed and just evaluated in terms of coherence of final (expected utilities/revealed preferences) outcomes. It is a matter bearing some resemblance to the "as...if" discussion, and also to entrenched debates in psychology between "behaviourist" and "cognitivist" views (whether "strong", à - la Chomsky, or much weaker ones à - la Johnson-Laird or Lakoff...). We do not have the arrogant casualness by which many practitioners of economics switch from one to the other. However, just note that the experimental results on heuristics, etc. are equally damaging for the defences of standard rationality in both view. So, for example, not only one finds "cognitive incoherence" but also revealed behaviours might well display "pessimisation" (!) as opposed to "maximisation" of utility (Herrstein and Prelec (1991)).
} 
common to human decision makers (whether individuals or organisations): .. after all, pushing it to the extreme, the collective evolution of human cultures has not been drawn from repeated trials on lotteries but on quite diverse experiences having nonetheless in common uniqueness features, out of which our cognition and beliefs had to make some precarious sense, ... from the threats in the forest to deaths of the relatives, from unexpected kin's violence to the discovery of fire and microprocessors... ${ }^{14}$.

\section{Endogenous Preferences.}

The separation from the previous point is somewhat arbitrary: indeed, the just mentioned heuristics and behavioural patterns often entail preferences which are state dependent. Status quo biases are a case to the point: the reference is not some invariant utility - however defined - but “... where I was, what I had, etc., at time t minus one..." 15. Moreover, it has been shown, the framing of the problem shapes revealed preferences (a huge literature in the field of marketing points in this direction, but particularly sharp experiments are in Kahneman et al. (1991)) and so do authority relations (cf. Milgram (1974)).

Endogenous preference may be often driven by the attempts to reduce regret and cognitive dissonance (cf. Festinger (1957)): that is, as we put it jokingly in Dosi and Metcalfe (1991) citing a pop song from the 60's, “...if you cannot be with the one you love, love the one you are with... !". And, finally, of course, endogeneity of preference is likely to stem from social imitation and other forms of social interactions (such as Veblenian "conspicuous consumption" and "snob effects", etc. ;: an early discussion is in Leibenstein $(1950))^{16}$.

\footnotetext{
${ }^{14}$ To our, limited, knowledge, one of the few exploratory attempts to positively account for "rational biases" as crucial clues on cognitive patterns in Margolis ( 1987). Totally sharing the idea that they should not be simply dismissed as pathologies (cf. Tordjman (1996)), in another work it is suggested that they could indeed provide a crucial collective evolutionary role, at least with regard to a particular one (i.e. overconfidence and illusion of control) (Dosi and Lovallo (1995), see also below).

${ }^{15}$ Which, of course, is in open violation of any standard, utility - based, decision - theoretic approach, whereby preferences are supposed to be defined on levels and not history-dependent variations and, moreover, are supposed to change on a time scale that is significantly slower than decisions and random occurrences of "nature".

${ }^{16}$ In economics, empirical studies of preference formation were a lively field of investigation in the 50's and 60's (cf. Katona (1951), and (1968)) but were pushed aside by a new generation of believers in expected utility theory. Among the few contemporary discussions and formal models dealing with these issues in economics cf. March (1988), Akerlof and Dickens (1982), Kuran (1991), Brock and Durlauf (1995)).
} 


\section{Collective Beliefs, Behaviours and learning.}

What said so far on cognition, judgement, etc. applies in principle also to all set-ups where individual agents may be assumed, in a first approximation, to act as insulated entities (notwithstanding, of course, the whole experience of socialisation they carry with them...). Other circumstances, however, are explicitly and immediately social: multiple-actors decision-making, such as those required by "teams", economic organisations and other institutions belong to this group (for a thorough discussion, cf. March (1988 and 1994).

Once more, it would be futile to try to review the enormous literature in the field. Let us just offer a few comments.

First, the evidence suggests that, if anything, collective decision making rather than curbing the judgmental "biases" mentioned earlier (say, via some equivalent of a "law of large numbers") tends on the contrary to reinforce them (Lovallo (1996), March (1994)).

Second, the "opaqueness" of the relationship between beliefs, behaviours and outcomes undermines the usefulness of representing multi-actor choice in terms of the canonical, linear, sequence outlined at the beginning of section (ii). Rather the general case seems to fit quite well the observation of Purkitt and Dyson (1990), who - describing the decision process during the Cuban missile crisis - note the general lack of "explicit linkages between information, a sense of the problem and problem responses" (!!) (Purkitt and Dyson (1990), p. 363). On the contrary, the archetypical decision-process, and, dynamically, the archetypical learning process, might fit quite well the garbage can model (Cohen, March and Olsen (1972)).

That is,

\footnotetext{
"in a garbage can process, it is assumed that there are no exogenous, time-dependent arrivals of choice opportunities, problems, solutions, and decision-makers. Problem, and solutions are attached to choices, and thus to each other, not because of any means-ends linkage but because of their temporal proximity. At the limit, for example, almost any solution can be associated to almost any problem - provided they are evoked at the same time” (March (1994), p. 200).
}

Third, multiple (and possibly conflicting) believes, goals, identities are likely to entail systematic decision inconsistencies, while learning and adaptation in these circumstances may well path-dependently strengthen these inconsistencies themselves (March (1988a) and (1994)). 
All this applies, even more so, in presence of multiple objectives of individual organisational members and of the organisation as a whole. (A related and more detailed discussion is in Dosi (1995a)).

\section{Rules, organisational routines and competencies.}

More generally, the issue of organisational learning involves the understanding of the processes by which organisational rules and action patterns ${ }^{17}$ change over time. Here, the relevant evidence coming from organisational studies - albeit far from clean and unequivocal - points at organisations as rather inertial behavioural entities which nonetheless are able to (path-dependently) change either under the pressures of external adversities and internal conflicts (cf. within an immense literature March and Simon (1958), March (1988a), Nelson and Winter (1982), Levinthal (1996b) and (1996a)). A particularly important analytical task, in this respect, concerns the identification of the nature of organisational routines (i.e. recurring, often complex, rather automatic, action patterns, set in an organisational context) and their changes : in our view, the discovery, establishment and modifications of routines are indeed an essential part of organisational learning... (On all these issues, cf. Cohen et al. (1995)). Routines, in this perspective, store and reproduce a good deal of the problem-solving competencies of the organisation and, together, its acquired patterns of governance of potentially conflicting interests among its members (Nelson and Winter (1982), Coriat and Dosi (1994)).

\section{Toward an "evolutionary" view of agency and learning?}

There are deep linkages among the findings, conjectures, "stylised facts" that we have telegraphically mentioned so far. In fact, we would dare to suggest that they may eventually fit well together in an "evolutionary" view of agency and learning, still to come, of which, however, one begins to appreciate some basic features ${ }^{18}$.

\footnotetext{
${ }^{17}$ Note that the two might not correspond at all, if by "rules" one means the explicitly stated operating procedures of organisation, and "action patterns" are what actually members of the organisation do...

${ }^{18} \mathrm{We}$ call it an "evolutionary view" because it is consistent with the evolutionary research programme as it is emerging in economics. Similar views, defined from the perspective of other disciplines, might well take different labels. For example, what we label here as "evolutionary" highly overlaps with the research programmes on "adaptive learning" and "mental models" in cognitive psychology and artificial sciences.... See also below.
} 
As we see it, such a view is going to embody the following "building blocks" namely

- Cognitive foundations focused on the dynamics of categories and mental models ;

- Heuristics as quite general processes for decision and learning;

- Context-dependence, and, relatedly, social embeddedness of both interpretative models and decision rules ;

- Endogeneity of (possibly inconsistent) goals and preferences;

- Organisations as behavioural entities in their own right (whose persistence and whose learning patterns certainly depend also on what the members of the organisation do and learn, but cannot at all be reduced to the latter) ${ }^{19}$;

- Processes of learning, adaptation and discovery apt to (imperfectly) guide representations and behaviours also (or primarily?) in ever-changing environments (so that, even if "you cannot bathe twice in the same river", one still tries to develop some robust representations of the river itself and some swimming heuristics...).

It is easy to understand the fundamental departures that this view entails vis-à-vis the canonical decision-theoretic one.

First, it abandons any "small world" assumption : in fact it is centred on a sort of open world postulate (one tries to make sense and survive in a world where there are many more things between heaven and earth than in anybody's philosophy... and, thus, one has always to face surprises...).

The clear down-side of this perspective is that, in practice and in principle, neither the agents we want to describe nor the theorist (if not a God with an infinitely accurate knowledge of all possible histories ${ }^{20}$ ) might be able even to define what is a "rational" decision procedure. The experimental evidence recalled above suggests indeed that most of us depart from it also when such procedures exist and are rather simple : but, to repeat, these "biases" might be precious symptoms of the ways we develop tentatively robust cognitive categories, search heuristics and decision rules in environments intrinsically characterised by knowledge-gaps and problem-solving gaps. The up-side is that one is also able to

\footnotetext{
${ }^{19}$ In fact, in Dosi (1995a), we push the argument further and suggest that, for many purposes, institutions rather than individual "rationality" and preferences ought to be considered as the primitives of the analysis.

${ }^{20}$ Note that this condition on infinitely perfect knowledge does not only apply to the case of genuinely evolutionary worlds: it holds also in all environments whose basic laws of motion are given and understood but exhibit non-linearities and sensitive dependence on initial conditions - such as chaotic dynamics. (A few more remarks are in Dosi and Metcalfe (1991) and the references there in).
} 
recombine cognitive categories in unlikely, highly conjectural, thought experiments and, paraphrasing March et al. (1991), "learn from samples of one or fewer"!!

Second, the evolutionary view, as we see it, is not committed to any procedural consistency : rather than blackboxing the algorithms for cognition and action, it considers the understanding of their mistake-ridden development as a crucial analytical task.

Third, it implicitly acknowledges the failure - as a general descriptive theory - of the axiomatic route and undertakes the less elegant path of a constructive theory, almost inevitably tinted by phenomenological specifications and restrictions.

The challenges and enormous difficulties involved in this research programme on the "evolutionary micro-foundations" of socio-economic change should be quite obvious to every reader. And these difficulties are compounded by the too frequent lack of robust taxonomies, models and generalisable "process stories" from the social disciplines where one should find them (e.g. psychology, sociology, etc.). In fact, in an ideal perspective, an economist with evolutionary/institutionalist inclinations ought to be able to get there some "level zero" first approximation properties - concerning e.g. cognition, social adaptation, collective learning, etc. - in order to build his microeconomic assumptions ${ }^{21}$. Unfortunately this too is rarely the case. Worse still, one has witnessed significant inroads of the canonical decision-theoretic axiomatics into the soft belly of many other social sciences (So that one finds child bearing, voting behaviours, drug addiction and, soon to come, infibulation as the equilibrium results of forward-looking rational choices...) ${ }^{22}$.

\footnotetext{
${ }^{21} \mathrm{~A}$ bit like, say, the relationship between physics and chemistry - whereby quantum physics provides, so to speak, the "microfoundations" of chemical laws - or, probably more pertinent, the relationship between chemistry and biology: while it is impossible to derive the notion of what a cow is just from the laws of chemistry, at the very least, the description of a cow should be consistent with the latter, and, at best, they ought to provide "level zero" bricks in a constructive theory of cows' development (For a fascinating discussion of generative processes of different levels of biological organisation, with some possible bearings on the issues of our concern here, cf. Fontana and Buss (1994)).

${ }^{22}$ It is impossible to discuss here the reasons for this phenomenon, which have to do, together with the incumbent epistemological looseness of those disciplines; the apparent rigour, parsimoniousness-onassumptions and generality of "economic imperialism" (...going back again to the strength of being rigorously wrong...); and, last but not least, a social zeitgeist which makes today "intuitively obvious" an account of behaviours in terms of utility maximisation as it was grace/temptation/Divine Providence up to three centuries ago... (On the latter, Hirschman (1965) presents a broad fresco on modern cultural history which helps in putting Gary Becker and disciples into perspective...; nearer to the disciplinary topics of this paper, cf. Hodgson (1988); more specifically, on the current interchanges between economic and sociology, see Baron and Hannan (1994); a less concise outline of the views on these themes of one of the authors is in Dosi (1995a)).
} 
Come as it may, the evolutionary research programme on agency and learning in economics cannot sit as a sheer user of "stylised facts" and workable generalisations from other disciplines. Rather, it seems to us, it has become urgent to pose to the practitioners of other disciplines the backlog of puzzling questions that one faces when dealing with the micro-foundations of evolutionary processes, and possibly acquire also some of their investigative skills ${ }^{23}$.

Well short of any comprehensive synthesis, it is useful to start, more modestly, from some basic taxonomical exercises.

\section{(iv) Learning processes : some taxonomies and appreciative theories.}

It is tautological that learning has a precondition in knowing less than one notionally could. And, of course, the simplest representation of a learning process - familiar from anyone's economic training - in terms of refinements of information partitions ; or updating of probability distributions ; or estimations of parameters of some model ; or statistically coherent comparisons among competing models...

However, if one accepts the view of cognition and problem-solving sketched above, one needs also to open up the "procedural black-box" and map different learning procedures into diverse types of problems and learning contexts. Let us consider them from a few, complementary, perspectives.

\section{Substantive and procedural uncertainty.}

One angle from which to look at learning processes focuses on the levels of cognitive and problem-solving complexity and its causes.

It is useful to distinguish between two different, albeit interrelated, sets of causes that make problems "hard", and that match our earlier distinction between knowledge-gaps and problem-solving gaps. In general, knowledge gaps arise from the lack of isomorphism

\footnotetext{
${ }^{23}$ The list of such questions is obviously very long: it includes e.g. the possible invariance in individual and organisational learning processes, the nature and evolution of "rules" for both cognition and action, better specifications of the social embeddedness of individual behaviours, and many others...
} 
between the environment and the agent's model of it. This is what we call in Dosi and Egidi (1991), paraphrasing H. Simon, substantive uncertainty. In turn, one may further distinguish between weak uncertainty (i.e. probabilisable risk) and strong uncertainty, involving genuine ignorance and intrinsic inadequacy of the mental models of the agents to fully capture the structure of the environment.

Conversely, problem-solving gaps entail different degrees of procedural uncertainty, with or without substantive uncertainty. (An impressionistic taxonomy is presented in figure 1). The distinction is clear, for example, with reference to puzzles like the Rubik cube. Here the structure of the problem is rather simple, ones the rules are known, and there is no substantive uncertainty : rather, solving the problem itself is the difficult task, involving relatively complex skills of sub-problem decomposition and sophisticated logical skills (Dosi and Egidi (1991)). Similar considerations apply to activities like theorem-proving and also, nearer to the economist's concerns, to many tasks associated with technological innovation such as the design and implementation of new products and processes.

The distinction helps also illuminating the somewhat different nature of the related learning processes. In the case of procedural uncertainty they concern primarily the development of problem-solving skills and heuristics.

Conversely when the latter can be reduced to rather simple and well understood algorithms, but uncertainty is primarily substantive, learning regards essentially the representation and framing of the problem ${ }^{24}$.

\section{Learning and the "logic of appropriateness".}

We have already mentioned that in most circumstances knowledge-gaps and problemsolving gaps are often related.

First of all, they are likely to appear together in evolutionary environments : it is straightforward that the continuous possibility of arrival of innovations implies "strong" substantive uncertainty, but, relatedly, this implies a symmetric procedural uncertainty (how can I cope with a changed environment? How can I, myself, innovate?).

Regarding the interdisciplinary efforts we have in mind, the works by Cohen and Bacdayan (1994) and Egidi (1996) on routines and learning are good examples.

${ }^{24}$ Incidentally note that the standard decision theoretic tool kit handles essentially substantive uncertainty (in its "weak" form) but is much less apt to deal with learning in the space of problemsolving procedures. 
Fig. 1. Substantive and procedural uncertainty : a taxonomy of problems

\begin{tabular}{|c|c|c|c|c|}
\hline \multicolumn{2}{|c|}{$\begin{array}{l}\text { Substantive uncertainty } \\
\text { Procedural uncertainty }\end{array}$} & certainty & $\begin{array}{l}\text { "weak" uncertainty } \\
\text { (risk) }\end{array}$ & "strong" uncertainty \\
\hline \multicolumn{2}{|l|}{ certainty } & $\begin{array}{l}\text { Trivial maximisation } \\
\text { problems (e.g. choosing } \\
\text { between winning or losing } \\
\text { one dollar with } \\
\text { certainty!!) }\end{array}$ & $\begin{array}{l}\text { lotteries and most } \\
\text { other set-ups considered } \\
\text { by standard theory of } \\
\text { decision under uncertainty }\end{array}$ & \\
\hline \multirow{2}{*}{$\begin{array}{l}\text { procedural } \\
\text { uncertainty }\end{array}$} & $\begin{array}{l}\text { with } \\
\text { finite } \\
\text { decision } \\
\text { trees }\end{array}$ & $\begin{array}{l}\text { puzzles like } \\
\text { the Rubik cube }\end{array}$ & $\begin{array}{l}\text { quite a few game-theoretic } \\
\text { problems ; relatively simple } \\
\text { economic decisions in } \\
\text { stationary environments }\end{array}$ & \\
\hline & $\begin{array}{l}\text { with } \\
\text { infinite } \\
\text { decision } \\
\text { trees }\end{array}$ & $\begin{array}{l}\text { proving theorems ; } \\
\text { developing technological } \\
\text { innovations on the grounds } \\
\text { of known } \\
\text { physical/chemical } \\
\text { principles... }\end{array}$ & $\begin{array}{l}\text { non-recursively computable } \\
\text { games }\end{array}$ & $\begin{array}{l}\text { adaptation and innovation } \\
\text { in evolutionary } \\
\text { environment }\end{array}$ \\
\hline
\end{tabular}


Moreover, the psychological evidence shows, the knowledge of the "structure" of the problem and problem-solving capabilities strongly influence each other: the way we perceive the structure of the problem largely depends on the kind of problem-solving skills we possess and, conversely, the problem-solving skills we develop are shaped by the ways we frame the problem (A germane discussion of the intertwining between a particular representation and a particular expertise is in Lane et al. (1996)).

The phenomenon hint at a more general property of decision making and learning which J. March has named the logic of appropriateness. As opposed to the archetypical decision process based on the evaluation of alternatives in terms consequences for utilities (i.e. the "logic of consequences") in the appropriateness logic,

\footnotetext{
"individuals and organisations fulfill identities, they follow rules or procedures that they see as appropriate to the situation...[while] neither preferences as they are normally conceived nor expectations of future consequences enter directly into the calculus...

Decision makers are imagined to ask (explicitly or implicitly) three questions :

1 - The question of recognition : what kind of situation is this?

2 - The question of identity: what kind of person am I?

Or what kind of organisation is this?

3 - The question of rules : what does a person such as I, or an organisation such as this, do in a situation such as this? (March (1994), pp. 57-8).
}

Note that under the logic of appropriateness, so defined, an important part of learning is about the understanding and implementation of the appropriate rules, and, in a broader perspective entails the co-evolution if identities, representations and rules.

It is our believe that indeed the "logic of appropriateness" informs a good deal of individual and organisational behaviours, and, to anticipate one of our conclusions, an urgent task ahead is to formally incorporate it into evolutionary theorising.

\section{Information, knowledge and learning. ${ }^{25}$}

Many contributors to contemporary evolutionary theory have drawn a fundamental distinction between information and knowledge. The former entails well stated and codified propositions about (i) states-of-the world (e.g. "it is raining”...), (ii) properties of nature (e.g. 
"...A causes B...")) ; (iii) identities of the other agents ("I know Mr. X and he is a crook...") and (iv) explicit algorithms on how to do things ${ }^{26}$. Conversely, knowledge, in the definition we propose here, includes a) cognitive categories; b) codes of interpretation of the information itself ; c) tacit skills, and d) search and problem-solving heuristics irreducible to well defined algorithms.

So, for example, the few hundred pages of demonstration of the last Fermat theorem would come under the heading of "information". Having said that, only some dozen mathematicians in the world will have adequate knowledge to understand and evaluate it. On the other hand, a chimpanzee, facing those same pages of information might just feel like eating them, and the vast majority of human beings would fall somewhere in between these two extremes... Similarly a manual on "how to produce microprocessors" is "information", while knowledge concerns the pre-existing ability of the reader to understand and implement the instructions contained therein. Moreover, in this definition, knowledge includes tacit and rather automatic skills like operating a particular machine or correctly driving a car to overtake another one (without stopping first in order to solve the appropriate system of differential equations ! !).

And, finally, it includes "visions" and ill-defined rules of search, like those involved in most activities of scientific discovery, and in technological and organisational innovation (e.g. proving a new theorem, designing a new kind of car, figuring out the behavioural patterns of a new kind of crook that appeared on the financial market...).

In this definition, knowledge is to varying degrees tacit, at the very least in the sense that the agent itself, and even a very sophisticated observer, would find it very hard to explicitly state the sequence of procedures by which information is coded, behavioural patterns are formed, problems are solved, etc.

In fact, as Winter (1987) suggests varying degrees of tacitness together with other dimensions (see figure 2 below) provide a sort of interpretative grid by which to classify different types of knowledge.

\footnotetext{
${ }^{25}$ This paragraph is largely drawn from Dosi (1995b).

${ }^{26}$ These four sets correspond quite closely to the codified aspects of Lundvall's taxonomy, distinguishing know-what, know-why, know-who and know-how (Lundvall (1995)).
} 
Tacit ---------------------------- Articulable

Not teachable ----------------Teachable

Not articulated -------------------Articulated

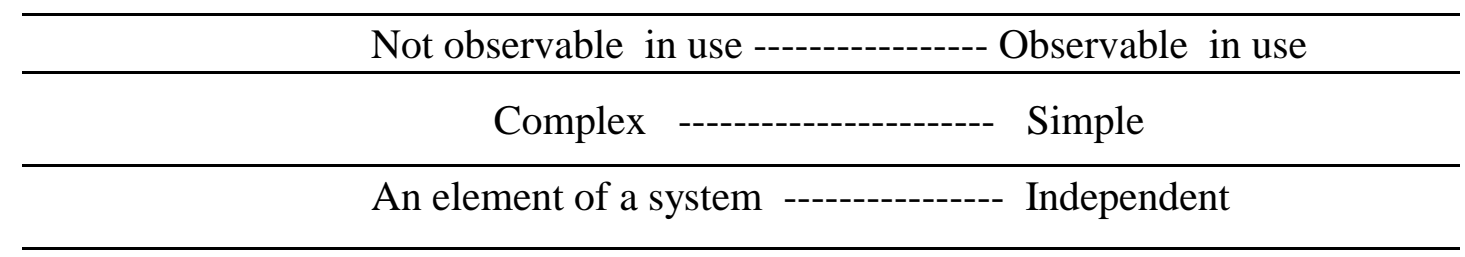

In this perspective, learning has three inter-related meanings.

First, rather obviously, it might involve, as in the conventional view, the acquisition of more information (conditional on the ability of correctly interpreting it).

Second, it entails various forms of augmentation of knowledge stricto sensu (which might well be independent from any arrival of new pieces of information).

Third, it might concern the articulation and codification of previously tacit knowledge (learning here involves so to speak "knowing better what you know").

In particular, this third aspect has recently drawn a lively debate concerning whether new information technologies accelerate the pace of codification and fundamentally upset the relative importance in contemporary economies between "information" and "tacit knowledge" (for different views on this point, cf. e.g. Foray and Lundvall (1996) and several contributions therein, Hicks (1995), Pavitt(1992)).

\section{Appreciative theories of knowledge accumulation and innovation.}

The levels of generality of most of what said so far - on decision, knowledge, learning processes, etc. - place the argument very near major foundational issues on cognition and agency in evolutionary environments. However, a good deal of (highly complementary) efforts by evolutionary-inclined scholars has been recently devoted to empirically grounded "appreciative" theories, to use the definition of Nelson and Winter (1982), in particular in the fields of technological and organisational learning. As a result - within the broad field of 
the "economics of innovation" - one knows much more as compared to, say, thirty years ago about the variety of processes by which knowledge is augmented and diffused in the economy (major contributions in this area include those of Christopher Freeman (cf. Freeman (1982) and (1994)), Nathan Rosenberg (cf. Rosenberg (1976), (1982) and (1994)), Keith Pavitt (cf. Pavitt(1984)), Richard Nelson (cf. Nelson (1987) and (1993)), Paul David (cf. David (1975) and (1985)) and others).

A first broad property (probably not surprising for non-economists, but with far reaching analytical implications) is the diversity of learning modes and sources of knowledge across technologies and across sectors. For example, in some activities knowledge is accumulated primarily via informal mechanisms of learning-by-doing and learning-by-interacting with customers, suppliers, etc. In others, it involves much more formalised activities of search (such as those undertaken in R\&D labs). In some fields, knowledge is mostly generated internally and specific to particular applications. In others it draws much more directly upon academic research and scientific advances. Recent research suggests that this diversity of learning modes may be a major determinant of the diverse patterns of evolution in industrial structures (e.g. in terms of distribution of firm sizes, natality and mortality of firms, corporate diversification).

An important step in the understanding of the "anatomy" of contemporary systems of production and knowledge accumulation has involved taxonomic exercises (e.g. Pavitt (1984)) trying to map families of technologies and sectors according to their sources of innovative knowledge and their typical innovative procedures.

At the same time, one has tried to identify possible invariance which holds across technologies, in the patterns of learning (notions like "technological paradigms", "regimes" and "technological trajectories" belong to this domain of analysis), and descriptive indicators for these same patterns (e.g. Dosi (1984)). Relatedly, variables like the levels of "innovative opportunity" associated to each technological paradigm, the degrees of "cumulativeness" displayed by technical advances, etc. have turned out to be quite useful in interpreting the determinants of the particular "trajectories" of innovation that one observes (Malerba and Orsenigo (1996)).

Second, in modern economies, firms are major, albeit by no means unique, repositories of knowledge. Individual organisations embody specific ways of solving problems that are often very difficult to replicate in other organisations or even within the organisation itself. In turn, organisational knowledge as mentioned earlier is stored to a good extent into the operating procedures ("the routines") and the higher level rules (concerning e.g. "what to do when something goes wrong", or "how to change lower level routines") that 
firms enact while handling their problem-solving tasks in the domains of production, research, marketing, etc.

Dynamically, technological knowledge is modified and augmented partly within individual firms, and partly through the interaction with other firms (competitors, users, suppliers, etc.) and other institutions (universities, technical societies, etc.). In these domains, growing literature on organisational capabilities and competencies has begun to explore the links between specific ensembles of organisational routines, types of organisational knowledge and corporate strategies (cf. Teece and Pisano (1994) introducing a special issue of Industrial and Corporate Change on these topics ; Lundvall (1996), Winter (1987) and (1988), Montgomery (1985) and also the somewhat more theoretical considerations in Dosi and Marengo (1994)).

Third, building upon the foregoing properties of the nature of technological learning and of the ways organisations incorporate knowledge, a few scholars have started to explore an explicit co-evolutionary view, whereby the accumulation of technological knowledge is shaped and constrained by the nature of the organisations and institutions where this knowledge demand and possibly trigger changes in corporate organisations and broader institutions Nelson (1983), Kogut (1993), Coriat and Dosi (1995a)).

\section{From appreciative theories to formal models.}

To what extent have formal theories been able to capture the foregoing "stylised facts", taxonomies and historically-grounded generalisations on collective learning ?

In order to offer some answers, let us rephrase the earlier taxonomic intuitions into a language nearer to possible modelling translations.

Recall the canonical steps of decision processes mentioned at the beginning of this work (i.e. representation; judgement; choice; action; consequences). When accounting for learning, each of these steps define some state-space of exploration. Accordingly, different classes of learning models can be distinguished with respect to the dimensions of the state space in which learning occurs. 


\section{Objects and state-spaces of learning processes.}

What is learning about?

There are basically four classes of objects of learning : a) the "states-of-the-world" (as in games against nature); b) other agents' behaviours (as in strategic games); c) how to solve problems (where the object of learning is not forecasting but designing algorithms); and d) one's own preferences (i.e. agents learn, so to speak, about their own characteristics and identity).

Note, first, that a full fledged evolutionary model (yet to come) ought to be able to account for all four classes, and, even better, generate empirically testable conjectures on the coupled dynamics among the different learning processes.

Second, it might well be that different objects of learning might imply also different mechanisms of search and learning (as far as we know, no robust generalisation appears to be available on this issue : yet another question that ought to be sorted out together with cognitive psychologists, sociologists, etc...).

This categorisation of learning objects partially maps into different formal representation of the dimensions of the state-space in which learning is generally assumed to occur, namely :

a) the space of representations or models of the world, b) the space of parameters within a given model, c) the space of actions and d) the space of realised performance outcomes ${ }^{27}$.

In the former case, learning is modelled as a search for better representations of the environment in which the agent is operating. Agents are supposed to hold models of the environment either explicitly (as, within psychology and artificial sciences, in rule-based models) or implicitly (as in connectionist models) and learning is defined as a structural modification (and not just the tuning of parameters) of the models themselves. Note that in the expression "better representation", better can have two very different meanings : it can either indicate better performing models, that is yielding more effective action, or more knowledgeable models, that is producing better predictions of the state of the environment. In the case where "better" means "better performing", the agent is assumed to adjust behaviours according only to the payoffs he receives, and a completely wrong representation which by chance produces effective action in relation to the actually experienced states of the world has to be preferred to an "almost" correct representation which, though being

\footnotetext{
${ }^{27}$ The mapping with the above classification is imprecise also in the sense that one leaves out, as most of the formal literature does, endogenous changes in goals and preferences.
} 
"close" to the real model, produces less effective actions in some of the same states of the world. But a similar question arises also when "better" means "better predicting", both because, in a similar fashion, bad representations which produce good predictions are preferred to good representations which produce worse prediction, and also because the very perception of what is a good prediction depends on the model itself : for instance a change in the state of the world form $s_{i}$ to $s_{j}$ might not be perceived as such by the agent whose information partition has $s_{i}$ and $s_{j}$ in the same equivalence class, and, thus, the agent is led to think that his model has not decreased his predictive power (see also below).

Learning in the space of parameters assumes that the model of the world is given in its functional structure and is equal or at least isomorphic to the "real" one and learning is just a refinement of the estimation of some unknown parameters. A typical example is Bayesian learning, where the learning agent updates his probability estimates within a given and immutable set of categories which constitute a partition of the real world (whatever that means).

Learning in the space of actions assumes instead that either the representation is constant or that it does not exist at all. As we shall see, this is typically the case of simple stimulus-response models of learning and most of the evolutionary games models, where the learning is simply modelled as a selection process in the space of alternative actions.

Finally, learning can be modelled as a dynamic process in the space of realised performance outcomes, whereby the actual process of learning is not modelled at all but the model considers only its results in terms of dynamics in the space of some performance parameters. Typical examples can be found in models of technological learning, where learning is a stochastic process in the space of productivity coefficients.

It is clear that a) implies b) implies c) implies d): learning in the space of representations involves also the possibility of parameter estimates within a given structural form, a selection process among possible actions ${ }^{28}$, and of course results into some movement in the space of performance outcome. Thus modelling strategies which remain at the higher level of description and do not explicitly address the "deeper" cognitive search and behavioural adaptation either assume that the latter has been "solved" (for instance the "right" information partition has been found) or, acknowledging the relevance of those lower levels, they only model, more parsimoniously, a "reduced form".

\footnotetext{
${ }^{28}$ Note that actions might be considered part of the representation, as it is the case, for instance, when representations are modelled as condition-action rules.
} 


\section{Domains and constraints of learning processes.}

Given the underlying object of learning or, more formally, the dimensions of state space of learning dynamics, what constraints does one assume on the domains of learning processes themselves?

Here the most important distinction is between search/adaptation over a fixed menu of possibilities which are all accessible from the start to all agents vs. an open-ended dynamics where the discovery of genuine novelties is always possible. As we shall illustrate below, this distinction marks an important cleavage between alternative modelling frameworks.

If all the notional elements of the learning set are known from the start, agents might be assumed to attach probabilities to each of them and to their consequences, thus possibly using some inferential procedure to adjust their behaviours. (Here the basic paradigm is the Bayesian model). Or, often to the same effects, the sheer availability of all possible behaviours in population, given a stationary environment, establishes an environmental landscape in which it might be too difficult to define the adaptation drive at work and the related equilibria. (The philosophy of evolutionary games' is near to this spirit). Conversely, whenever novelties happen to persistently appear, probability updating are likely to turn out to be a rather clumsy learning procedure, since the state-space can no longer be usefully partitioned, due to the emergence of surprises and unforeseen (indeed, unforeseeable) events $^{29}$.

And, rather symmetrically, in population-based adaptive frameworks, the systematic appearance of novelties implies also an ever-expanding payoff matrix, continuously deformed by the interaction with new events and strategies ${ }^{30}$.

\footnotetext{
${ }^{29}$ It is true that probabilistic decision making allows for the introduction of a complement-to-theuniverse category (i.e. "all other events") in the information partition in order to close it, but in presence of genuine novelty (that is, "strong" substantive uncertainty, as defined above), it is unreasonably farfetched to assume that a probability could be attached to an unbounded set of events not even conceivable for the decision-maker. In the debate between the advocates of non-probabilistic approaches to uncertainty vs. supporters of the probability paradigm, see also Dubois and Prade (1988) and the references therein.

${ }^{30}$ In biological models, this corresponds to endogenous landscapes with no ex-ante definable fitness maxima .
} 


\section{Mechanisms of learning.}

The very notion of learning, also in the common language, imply a sort of reference yardstick, measuring some "improvement", however defined, in terms of e.g. cognition, forecasting abilities, collectively assessed performances, inwardly evaluated utilities, etc.

Assume, in a first approximation, that those same criteria are what drive the learning process. Even then, one may well find quite different mechanisms at work (and correspondingly different formal "laws of motion"). For example, "learning" could be simply a shorthand characterisation of a population-level selection mechanism involving differential reproduction of entities (e.g., in economics, business firms) carrying different behavioural, organisational, or technological traits. Or, it may mean an adaptation process driven by stimulus-response adjustments, without any explicit underlying cognitive process. Or, again, it could be based on agent-specific mechanisms involving expectations, internal involvement of credit, etc. While in the simplest specifications of the object of learning the three types of dynamics may well turn out to be (asymptotically) equivalent, they might make indeed a major difference, in terms of finite-time properties even for simple learning processes, and, a fortiori, in terms of long-term outcomes of discovery and adaptation in more complex evolutionary environments.

With respect to the modelling frameworks, at one extreme, stimulus-response adaptation (with or without environmental selection) implies agents without any explicit "reasoning", memory or inferential algorithms leading from the outcomes of their actions to the revision of their future decision rules. At another extreme, agents may be modelled as forward-looking users of the best available information (at least in terms of what their bounded competencies allow).

In some peculiarly simple circumstances, the two apparently opposite mechanisms of learning can be shown to lead to identical limit outcomes (...which look too often like all those cases whereby electrical shocks to rats leads them to converge to those equilibrium behaviours predicted by rational-expectation rats facing the same environment ...) ${ }^{31}$.

However, in most other set-ups, the specification of the mechanisms of learning does make a difference : this is an area where unfortunately, to our knowledge, one does not have yet empirically robust generalisations which can be easily translated into formal modelling assumptions.

On the grounds of the foregoing distinctions, fig. 3 presents an impressionistic classification of examples of each genre in the current modelling literature. These 
differences in learning processes can also be formally accounted as variations and restrictions on the grounds of a unified basic representation. This is what we shall attempt to do in the next section.

${ }^{31}$ And this is indeed the amusing behavioural support that Lucas (1986) suggests for the rational expectation hypothesis. 
Fig. 3. Dimensions of learning and constraints on learning process : a guide to the (modelling) literature

Learning spaces

\begin{tabular}{|c|c|c|c|c|c|}
\hline & & actions/strategies & $\begin{array}{l}\text { Representation/ } \\
\text { "Models of the world" }\end{array}$ & $\begin{array}{l}\text { Realised } \\
\text { Performances }\end{array}$ & Preferences \\
\hline \multirow[t]{2}{*}{$\begin{array}{l}\text { Domains and } \\
\text { constraints on } \\
\text { learning } \\
\text { processes }\end{array}$} & "fixed menus" & $\begin{array}{l}\text { learning in game- } \\
\text { theoretic set-ups } \\
\text { "evolutionary" games } \\
\text { adaptive learning in } \\
\text { multi-arm bandit } \\
\text { problems (e.g. Arthur (1993) } \\
\text { self-organisation models } \\
\text { à la Lesourne (1991) } \\
\text { urn models and other } \\
\text { types of innovation } \\
\text { innovation-adoption models } \\
\text { (cf. Arthur et al. (1984), } \\
\text { Arthur and Lane (1993). } \\
\text { Kirman (1994), etc.) } \\
\text { special cases of evolutionary } \\
\text { models (cf. Winter (1971)) } \\
\text { (implicitl } \\
\text { enviro }\end{array}$ & $\begin{array}{l}\text { Bayesian reduction } \\
\text { of information } \\
\text { incompleteness in } \\
\text { games } \\
\text { models in stationary } \\
\text { Arifovic (1994)), } \\
\text { al.(1990)) }\end{array}$ & $\begin{array}{l}\text { learning-by } \\
\text { doing and } \\
\text { by using } \\
\text { for given } \\
\text { best-practice } \\
\text { technologies } \\
\text { (e.g. Silverberg } \\
\text { et al. (1988), } \\
\text { Eliasson (1985)) }\end{array}$ & $\begin{array}{l}\text { Socially } \\
\text { shaped } \\
\text { preferences } \\
\text { (e.g. Kuran } \\
\text { (1987), } \\
\text { Brock and Durlauf } \\
\text { (1995), } \\
\text { Akerlof and } \\
\text { Dickens } \\
\text { (1982)) }\end{array}$ \\
\hline & $\begin{array}{l}\text { "open-ended } \\
\text { sets of } \\
\text { learning objects }\end{array}$ & $\begin{array}{l}\text { behavioural search in Lindgren } \\
\text { Silverberg and Verspagen (1995 } \\
\text { Andersen (1994) } \\
\text { Marengo and Tordjman (199 } \\
\text { Bassanini and Valente (1994) }\end{array}$ & Tarengo, & $\begin{array}{l}\text { open-ended } \\
\text { technological } \\
\text { search such as } \\
\text { in Nelson and } \\
\text { Winter (1982), } \\
\text { Silverberg and } \\
\text { Verspagen (1994); } \\
\text { Chiaromonte, } \\
\text { Dosi and } \\
\text { Orsenigo (1993); } \\
\text { Dosi } \\
\text { et al. (1995) }\end{array}$ & \\
\hline
\end{tabular}




\section{(v.) A basic model and various specifications.}

Let us consider a standard decision problem whereby an agent faces an environment which can be in one out of an enumerable set of elementary outcomes :

$$
\mathrm{S}=\left\{\mathrm{s}_{1}, \mathrm{~s}_{2}, \ldots, \mathrm{si}_{1}, \ldots\right\}
$$

In most relevant economic problems, the agent will not know the whole set of states of the world $\mathrm{S}$ (and even less so their casual links), but he will possess only an imprecise and partial representation thereof :

$$
\Theta^{t}=\left\{\vartheta_{1}^{t}, \vartheta_{2}^{t}, \ldots, \vartheta_{j}^{t}, \ldots\right\} \text { where } \vartheta_{j}^{t} \subseteq S \text { and } \Theta^{t} \subseteq 2^{S}
$$

Each $\vartheta_{\mathrm{j}}$ includes all the states-of-the-world which the agent considers as possible, or cannot discriminate, when one or more elementary outcomes contained in $\vartheta_{j}$ occur (note that in most economic models it is assumed that $\Theta^{t}=\mathrm{S}$ - meaning that the agent "knows" the structure of the world or, at least, $\Theta$ is assumed to be a partition of S). Assuming instead that more generally $\Theta \subseteq 2^{S}$ we have a representation which can account for :

1. complete ignorance :

$$
\vartheta_{i}^{t}=S \quad \text { for every } \mathrm{i}=1,2 \ldots . \mathrm{n}
$$

2. partial ignorance of some states of the world, if

$$
\mathrm{U}_{\mathrm{i}} \vartheta_{i}^{t} \subset S
$$

i.e. the agent may be "surprised" by some events which he did not even think of.

3. hierarchies of hypotheses and/or partially overlapping hypotheses :

$$
\begin{aligned}
& \vartheta_{i} \subset \vartheta_{j} \text { or, more generally, } \\
& \vartheta_{i} \cap \vartheta_{j} \neq \varnothing \text { and } \vartheta_{i} \neq \vartheta_{j}
\end{aligned}
$$

4. systematic mistakes, when an outcome is believed to occur when it does not, and is not thought to be possible when it actually does occur.

Let then assume that the agent is notionally endowed with an enumerable set of possible actions :

$$
\mathrm{A}=\left\{\mathrm{a}_{1}, \mathrm{a}_{2}, \ldots \mathrm{a}_{\mathrm{j}}, \ldots\right\}
$$

At any point in time, the agents holds a finite behavioural repertoire constructed from the basic "atomic" actions contained in A, subject to revision, modification and 
recombination. Note that in general one ought to allow the agent to know only a subset of all notional repertoire derivable from $\mathrm{A}$. Let us call the known repertoire at time $\mathrm{t}$ :

$$
\Xi^{t}=\left\{\xi_{1}^{t}, \xi_{2}^{t}, \ldots, \xi_{j}^{t}, \ldots\right\} \text { where } \xi_{j}^{t} \subseteq A \text { and } \Xi^{t} \subseteq 2^{A}
$$

It must be pointed out that $\Theta^{t}$ and $\Xi^{t}$ do not only reflect the agent's sharpness at interpreting the information coming from the environment, by defining how sharp or coarse are his categories (information processing capabilities, in the standard decision-theoretic jargon), but embed also a lot of the "cognitive order" that the agent imposes on the world. $\Theta$, in particular, contains the variables and categories that the agent perceives as relevant to the representation problem in the undifferentiated flow of signals coming from the environment.

Hence, beyond very simple and special cases, $\Theta^{t}$ and $\Xi^{t}$ entail some sort of grammar determining the legal cognitive and behavioural structures that can be notionally generated. Genuinely constructive models of cognition and problem-solving ought to tackle the processes of search in some functional space of which some $\vartheta$ 's are themselves the outcome. So, for example, the proposition "we are in the state $\vartheta_{i}$ " is generated through cognitive operations attributing a semantic value to the signals received in the environmental state interpreted by the agent under $\vartheta_{i}$. As we shall see we are unfortunately still very far from the fulfilment of this research task (see however Fontana and Buss (1996) for a fascinating framework which might possibly be applied also to these problems).

The set of "perceived" histories at time $\mathrm{t}$ contains some finite-length histories of perceived states of the world and perceived actions which have occurred up to time $t$ :

$$
\begin{gathered}
H^{t}=\left\{h_{k}^{t}\right\} \quad, k=1,2, \ldots, t \\
\text { where } h_{k}^{t} \in \Theta^{k} \times \Theta^{k+1} \ldots \times \Theta^{t} \times \Xi^{k} \times \Xi^{k+1} \ldots \times \Xi^{t}
\end{gathered}
$$

We have repeatedly emphasised that a satisfactory understanding of learning processes entails an account of cognitive categories and "mental models" which attribute a causal structure (an "interpretation") to perceived histories. In this formal setting, an interpretation or model can be seen as an algorithm which attribute a causal sense to perceived histories or a subset of them. Call such "models" :

$$
\Phi^{t}=\left\{\varphi^{t}(h), h \in H\right\}
$$

Notice that, first, particular cases include those whereby agents retain only a dissipating memory of their representations and actions. Second, a single agent may well hold multiple (and contradictory) models at each t. Third, in terms of most current models, 
notice also that a sort of naive "transparency assumption" rules out an interpretation stage (everyone knows what really happened...)

A decision rule is a mapping between interpretations, so defined, and action repertoires :

$$
r_{i}^{t}: \Phi^{t} \rightarrow \Xi^{t}
$$

A special case, which is commonly considered in the models discussed below, is when the mappings $r^{t}$ define a probability distribution over the set of action repertoires.

An agent's decision-making capabilities at time $t$ can therefore be represented by the (finite) set of decision rules it holds :

$$
\Re^{t}=\left\{r_{1}^{t}, r_{2}^{t}, \ldots, r_{q}^{t}\right\}
$$

When the agent acts upon the environment, it receives a "response" (or an outcome) out of a set $P$ of possible responses:

$$
p^{t}: S \times A \rightarrow P
$$

However, in general, the agent will only know an imprecise and partial representation of such outcomes. Moreover it might well change over time its evaluation criteria (i.e., in standard language, its "preferences"). Call payoffs such evaluations in terms of some desirability criterion (being it utility, peace of mind, problem-solving achievement, morality, pleasure and pain, minimum regret, etc.) :

$$
U^{t}=\Psi^{t}\left(p^{t}\right)
$$

Hence, let us define a payoff function as :

$$
\pi^{t}: \Theta^{t} \times \Xi^{t} \rightarrow U^{t}
$$

On the grounds of this very general sketch of a decision-making model, we can reexamine the different loci of learning discussed earlier in a more qualitative fashion. However, it might be useful to begin with some extreme examples in order to flag some basic points of this exercise.

First, note that the most familiar economic models of decision-making assume that :

a. $\Theta$ 's are strictly partitions of S ;

b. there is a known and, often, trivial set of action repertoires $\Xi$ and, hence, the distinction between $\Xi$ and $\mathrm{A}$ is redundant (witness the fact that economists and decision theorists are generally more comfortable in dealing with metaphors such as lotteries, where the very 
action - putting a finger on the object of the set - could be performed by any chimpanzee, rather than building computers, proving theorems, etc.) ;

c. "interpretations" are always identical to "true" stories, and, again, the $\Phi$ algorithm is redundant ;

d. evaluation criteria on outcomes are time-invariant so that one can innocently assume also invariant payoff functions which drive learning.

All in all, under this scenario, some well specified dynamics on learning about the mapping $S \times A \rightarrow R$ turns out to be everything which one needs to know.

Second, at the opposite extreme, a caricatural "sociological" might well claim that :

a. as a first approximation, $\Xi$ 's are invariant in $\mathrm{t}$ (i.e. "you do what you are supposed to do..”) ;

b. outcomes are always "good" (Mr. Pangloss' rule : we live in the best of possible worlds. For simplicity, $\mathrm{U}^{\mathrm{t}}$ is always in the neighbourhood of some $\bar{U}$, irrespectively of $\mathrm{p}^{\mathrm{t}}$ :"like what you get no matter what...”) ;

c. learning is basically about the endogenous development of representations, interpretations and "utilities" which fulfil the invariance in the $\Xi$ 's and U's.

No doubt that the former caricatural model has been taken formally more seriously than the latter. However, as a first descriptive approximation, the authors of this essay, tend to bet on the worth of the latter.

\section{1) Learning about the states of the world ${ }^{32}$.}

This obviously implies changing the representation $\Theta^{t}$. Moreover, these changing representations could simply involve search in the parameter space or, more fundamentally, the very structure of the model of the world itself.

Suppose for instance that $\mathrm{S}$ is governed by a stochastic process. The agent might know which kind of stochastic process generates the sequence of states of the world - e.g., for sake of illustration, a Markov process - and have only to "learn" the correct estimate of

${ }^{32}$ Here and throughout we shall hint at some basic and proximate structure of a few models, with inevitable gross approximations on both the detailed formalisms and assumption refinements. Apologies to misinterpreted authors are due. 
the parameters - e.g. Markov transition probabilities -. Or he might ignore the nature of the stochastic process itself or even that there is a stochastic process at all ${ }^{33}$.

Note also that the possibility for the decision maker to learn about the stochastic process in $S$ depends on the representation $\Theta^{t}$ he holds : only if the latter discriminates among the states in the sequence $\mathrm{s}^{1}, \mathrm{~s}^{2}, \ldots ., \mathrm{s}, \ldots$ in separate categories will the agent have a chance to correctly learn the underlying stochastic process . But the converse might also be true : having chunks of states held together might make it easier to find deterministic patterns out of what might look like a random sequence.

The nature and degree of uncertainty about the stochastic process depends also on the general causal structure of the environment. In particular, we can distinguish among :

- interactions with nature without feed-back;

घ interactions with nature with feed-back;

- multi-agent strategic interactions (including standard game-theoretic ones). ${ }^{34}$

A fundamental case for our purposes arises when the actions of the agent himself generate new states of the world which did not exist in the original notional set S. Innovative behaviours are a typical case to the point: new environmental opportunities are endogenously created, thus making also any sharp distinction between exploration over $\mathrm{S}$ and exploration over A only a first cut approximation ${ }^{35}$. As argued in Dosi and Egidi (1991), it might well be the case that in such innovative environment a) the set $\mathrm{S}$ loses the enumerability property, and $b$ ) even an agent who has a perfect knowledge of $S$ to start with will be bound to revise his representation.

2. Learning about the actions space (changing the repertoires $\Xi^{\mathrm{t}}$ ).

The set of action repertoires $\Xi^{\mathrm{t}}$ can be modified through time, reflecting the "technology" of the agent. New actions can be discovered which were not in the agent's

33 There exists ample experimental evidence that probability matching, which amounts to ignoring that data are generated by a stochastic process, is a typical judgmental bias which appears even in the behaviour of expert decision makers.

${ }^{34}$ A similar distinction is made in Marimon (1995).

35 This notwithstanding, we do maintain that it is a useful first approximation, and in that we take issues with the radical proponent of "social constructivism" (which in the formal framework presented here would also mean collapsing representations into actions). Putting it into a rather caricatural way, while we claim that a world with the atomic bomb entails a set of events different (and greater) than a world without it, we also maintain that any exploration in the problem solving space, no matter how well "socially constructed" will hardly allow violation of the law of gravitation or time-reversibility of actions. Several issues concerning the "social construction" of technological knowledge are discussed in Rip et al. (1995). From a different angle, collective learning processes are discussed in Lane et al. (1995). 
repertoire before, or existing actions can be combined in new ways : both circumstances are isomorphic to the search in the problem-solving space (and the related procedural uncertainty) discussed earlier..

\section{Learning about the payoff function (changing the mapping $\pi^{t}$ ).}

If the agent does not know $\mathrm{S}$ and $\mathrm{A}$ but holds only imprecise and partial representations thereof, a fortiori he will have an imprecise and partial knowledge of how the payoff function, as earlier defined, maps into "objective" outcomes. It is worth pointing out that most learning algorithms model learning as a modification of representation of the world and action repertoires where the learning agent adaptively develops quasi-payoffequivalent categories of events and actions, i.e. categories which tend to reflect the regularities of the payoff function, rather than the regularities of the underlying sets of states and actions. Thus, under some conditions, adaptive learning algorithms tend to produce a better knowledge of the payoff function than of the sets $\mathrm{S}$ and $\mathrm{A}$.

Note also that endogenous preferences cum reduction of cognitive dissonance etc. (see above) involve a dynamics in both $\pi^{t}$ and $\Theta^{t}$ conditional on past realisations (something which one hardly finds in any current model, evolutionary or not).

4. Learning about the decision rules (changing the set of rules $\Re^{t}$ ).

A basic (and again largely unresolved) issue concerns the dimension of the state space of rule search. In the spirit of the foregoing discussion, it ought to concern some (metaphoric) representation, internal to the agent, of the mappings on $\Theta^{t} \times \Xi^{t} \times \pi^{t}$. However, the generality of existing models are stuck to a much simpler view (a reduced form ? Or, rather, a trivialisation ?) with a fixed menu of rules to begin with and three, possibly overlapping, learning mechanisms, namely : first, some selection mechanism which modifies the weights attributed to each rule and therefore its probability of being selected for action; second, mechanisms for modifying the domain of applicability of a rule, that is the subset of the set of perceived histories which fire the rule ; and, third (often not easily distinguishable from the above), a process for generating new rules which previously did not exist, possibly by modifying or recombining in some way already existing ones.

What kind of formal modelling and results does one currently find? In the rest of this section we will discuss briefly some of the main classes of models. Departing from a sketch of the classical Bayesian leaning models, we will then consider a class of models which are 
evolutionary in the sense that they explicitly take on board learning and adjustment dynamics of some kind, although they tackle primarily adaptation rather than evolution stricto sensu : i.e. they still keep some "small world" assumption on S, A, etc. and moreover generally tend to rule out (with some noticeable exceptions) any endogeneity of the environmental (or cognitive) landscapes over which representations, actions and decision rules are selected. (Most of the work in this field comes under the heading of "evolutionary games").

\section{Bayesian Learning : single- and multi-agent without feedback.}

As a starting point, consider Bayesian learning in the single- and multi-agents situation without feed-back from the environment. A typical case is based on the assumptions that the state of the world is determined by some stochastic process and the agent(s) has to select at each time $t$ a proper action. Hence, the agent has to produce an estimate of the stochastic process and compute the expected utility of a course of action. A "subjectively rational" agent holds a prior distribution $\mu$ which he updates through a Bayesian rule, by computing a posterior distribution after observing the realisations of the stochastic process and the payoff received.

In the multi-agent case (Kalai and Lehrer (1993)), the prior distribution concerns the actions of the other players (their "types"). Contrary to the hypotheses which are made in the literature on e.g. rationalizable strategies, such a prior distribution does not require knowledge of the other agents' payoff matrices, but only of one's own; however, S and A must be common knowledge.

Bayesian updating processes in this case strongly converge ("strongly merge") if the sequence of posterior distributions converge, in the limit, to the real distribution on $\mathrm{S}$ (Blackwell and Dubins (1962)). But this can happen only if prior distributions attach positive probability to all and only the subsets of $S$ which have positive probability for the underlying stochastic process. This amounts to postulating perfect ex-ante knowledge of all possible events. Kalai and Lehrer (1993) show this result in a nxn game without feed-back, in which they assume agents do not have complete knowledge of the space of strategies of the other players, nor do they have to share homogeneous priors, but their prior must be "compatible with the truth", that is they have to attach positive probability to all and only the events which can occur with positive probability (the so-called "grain of truth" condition). 
Moreover Feldman (1991) ha shown that if the set A is non-enumerable, convergence of posterior distributions to the true one cannot be guaranteed.

\section{Stochastic Learning Models.}

Of course, Bayesian learning is highly demanding on the prior knowledge agents are assumed to have from the start (a point nowadays acknowledged also by scholars otherwise inclined to some "rationalist" axiomatics of learning processes).

A much less demanding way, common in the contemporary literature, to introduce learning is to suppose some form of selection process among a finite set of possible actions. Two modelling strategies are possible in this respect: on the one hand, models might assume the existence of a population of agents, each identified with one action ${ }^{36}$ and consider the learning/selection process taking place entirely at the population level. On the other hand, each agent could be modelled by a set of actions, with the selection process being a metaphor of its search capabilities (cf. Fudenberg and Kreps (1993), Kaniovski and Young (1994)). This distinction goes beyond the interpretation of the metaphor itself but - as will shall see - has some substantial consequences on the modelling strategy.

First, consider a face-value interpretation of standard evolutionary games. Indeed, evolutionary games assume away any problem of representation, both on states of world and on actions, and, so to speak, collapse learning of decision rules into selecting among a set of given behavioural repertoires (further assuming that such a selection process is exogenously driven by the environment). Agents carry no cognitive capability, but have basically two roles : that of carrying the "memory" of the system (e.g. that of being "replicators" of some kind) and that of introducing some exploration (via random mutation).

In one standard formulation, evolutionary game models (cf.. the pioneering work of Maynard Smith (1982) and, later, in economics e.g. the work by Friedman (1991) and Kandori, Mailath and Rob (1993), Young (1993) and Weibull (1995)) assume that there exists a population of $\mathrm{N}$ agents and a finite set of actions $\mathrm{a}_{1}, \mathrm{a}_{2} \ldots . . . \mathrm{a}_{\mathrm{k}}$. If we denote by $\mathrm{n}_{\mathrm{i}}(\mathrm{t})$ the number of agents adopting strategy $\mathrm{a}_{\mathrm{i}}$, the basic selection principle states that :

$$
\frac{n_{i}(t+1)-n_{i}(t)}{n_{i}(t)}>\frac{n_{j}(t+1)-n_{j}(t)}{n_{j}(t)} \quad \text { if and only if } \pi^{\mathrm{t}}\left(\mathrm{a}_{\mathrm{i}}, \mathrm{s}^{\mathrm{t}}\right)>\pi^{\mathrm{t}}\left(\mathrm{a}_{\mathrm{j}}, \mathrm{s}^{\mathrm{t}}\right)
$$

${ }^{36}$ Coherently with the terminology introduced in the basic model, we use the term action rather than the more common strategy for this kind of models. 
The fundamental selection principle therefore implies that actions which have higher payoff are increasingly sampled in the population. It is often (though not always) the case that this selection principle takes the special form of replicator dynamics equation, originally suggested by biological arguments (cf.. the pioneering work of Maynard Smith (1982) and, earlier, Fisher (1930)) but widely used also in economic models - though with less convincing arguments ${ }^{37}$

$$
n_{i}(t+1)=g\left(\pi^{t}\left(a_{i}, s_{t}\right)-\bar{\pi}^{t}\right) n_{i}(t)
$$

where $\bar{\pi}^{t}$ is the average payoff across the population.

Learning is driven by the joint action of a selection principle and a variation mechanism, i.e. the constant introduction of search by means of random mutation, whereby some agents mutate their strategy with some given (small) probability.

Originally, mutation was conceived as a pointly and isolated phenomenon (cf. Maynard Smith (1982)), introduced as a device for studying the evolutionary stability of equilibria. An equilibrium was said to be evolutionary stable if, once achieved, it could not be disrupted if a small proportion of mutants appeared in the population. More recent developments (cf., for instance, Kandori, Mailath and Rob (1993), Foster and Young (1990), Fudenberg and Harris (1992)) of stochastic evolutionary games, have incorporated mutation as a continuous process : hence the equilibria generally emerge as limit distributions of some dynamic process (in some cases, however, ergodicity is lost such as in Fudenberg and Harris (1992) and in Kaniovski and Young (1994)).

Further developments concern the nature of the selection process in (2). The dynamics can in fact be made dependent upon the past history of interactions, as summarised by the relative frequencies of actions within the population and/or by the some sample of the past payoffs. Along these lines, Young (1993) considers a stochastic version of a replication mechanism whereby an action diffuses across the population according to a sample of the payoff obtained in the last few periods. Along similar lines, a class of models (see especially Milgrom and Roberts (1991) and Fudenberg and Kreps (1993) and Kaniovski and Young (1994)), considers more sophisticated agents, by endowing them with some form of memory which keeps track of the consequences of actions and of the other players' replies in the past. Learning becomes a process of selection of sequence of actions which are best reply to sampled strategies (Kaniovski and Young (1994)) and might induce the emergence of "conventions", i.e. stable patterns of behaviour (which are at least locally stable Nash equilibria; Young (1993) shows it in the cases of very simple memory endowments).

37 Many recent models have worked with a more general setting where broader classes of selection rules are considered, rather than strict replicator dynamics (cf., for instance, Kandori, Mailath and Rob 


\section{Stochastic models with self-reinforcement.}

In evolutionary games it is customary to assume that actions which have better performed in the past tend to diffuse more rapidly across the population of players, while the selection mechanism itself is either a replicator equation or is constructed via adaptation driven by infinitely frequent interactions among agents at each iteration (as in Kandori et al. (1993)). Other kinds of models consider different mechanisms of diffusion, where agents choose an action according to some simple algorithm, such as a majority rule (that is, choose the action which is adopted by the majority of some observed sample of the population).

First, if one considers a finite population of players, the number of agents who select action $\mathrm{a}_{\mathrm{k}}$ at time $\mathrm{t}$ defines a Markov chain where transition probabilities depend on actual frequencies of actions in the population. For instance, assume a population of $\mathrm{N}$ individuals and $A=\left\{a_{1}, a_{2}\right\}$. Agent $i$, who has selected action $a_{1}$ at time $t-1$, switches at time $t$ to action $a_{2}$ with probability :

$$
P_{i}^{t}\left(a_{1} \rightarrow a_{2}\right)=\alpha \frac{n_{2}(t)}{N}+\varepsilon
$$

where $\mathrm{n}_{2}(\mathrm{t})=\mathrm{N}-\mathrm{n}_{1}(\mathrm{t})$ is the number of agents selecting action $\mathrm{a}_{2}$. The $\alpha$ parameter measures the weight of the self-reinforcing component of the selection process, while $\varepsilon$ captures components which are indipendent from the choice of the other agents ${ }^{38}$. It is possible to show the existence of a limit distribution (cf. Kirman (1992) and (1993), Orléan (1992), Topol (1991)). Depending on the values of $\alpha$, the population may oscillate between the two states with the limit distribution itself determining the average frequencies at which the system is observed in each state in the limit.

A second modelling strategy considers infinitely growing populations, where at each time step $t$ a new agent makes a once-and-forever choice of action $a_{k}$ with probability depending on the relative frequencies of past choices. In these models (cf., among the others, Arthur, Ermoliev and Kaniovski (1983), Dosi and Kaniovski (1994), Kaniovski and Young (1994), Fudenberg and Kreps (1993)) learning takes place primarily at the population level (agents cannot change their decision) and this occurs in a typical "incremental" fashion.

The population dynamics can be described by an equation of the type :

(1993), Kaniovski and Young (1994)).

${ }^{38}$ As mentioned above, we skip here any technical details, such as, for example, the not-so-minor difficulty of keeping such dynamics as those represented in eq. 3 consistently on the unit simplex. 


$$
x_{k}(t+1)=x_{k}(t)+\frac{1}{N_{t}}\left\{\left[f_{k}\left(x_{k}(t+1)-x_{k}(t)\right]+\varepsilon(x(t), t)\right\}\right.
$$

where $\mathrm{N}_{\mathrm{t}}$ is the size of the population after $t$ arrivals of "new agents", $\mathrm{x}_{\mathrm{k}}(\mathrm{t})$ is the share of the population which has chosen action $a_{k}$ and $\varepsilon(x(t), t)$ is a stochastic term with zero mean, independent in $\mathrm{t}$.

The function $\mathrm{f}_{\mathrm{k}}$ embeds possible self-reinforcing mechanisms, and its functional form determines the number and the stability properties of fixed points. In case of multiple equilibria, the process is generally non-ergodic (i.e. it displays path-dependency), and convergence to one or another equilibrium depends on initial conditions and sequences of "early" choices (cf. Arthur et al. (1984), Glaziev and Kaniovski (1991)).

It is worth pointing out that in the former class of models with finite population, also in the limit the population might keep oscillating between states and spend some fraction of time on each of them. Models can only predict the limit distribution and, possibly, the average time the population spends on each of the states which have in the limit positive probability measure ${ }^{39}$. In the latter infinitely increasing population models, instead, the size of the population goes to infinity in the limit and the system will almost surely be found in one of the absorbing states. But if such absorbing states are multiple, which one is selected depends on initial conditions and on the path followed by the system in finite time ${ }^{40}$.

Moreover, in both classes of models, it is assumed that agents base their decisions on observed frequencies. Thus, if these models are to be taken as representation of distributed, agent-based, learning, such information must be somehow available to them : for example, a plausible interpretation of e.g. Arthur, Ermoliev and Kaniovski (1983) is that frequencies are

39 It is true that after determining the limit distribution as $t \rightarrow \infty$, one might collapse it to a measure-one mass corresponding to one of the equilibria by further assuming that $\varepsilon \rightarrow 0$ (i.e. that the "error" or "search" term vanishes). However, it seems to us that this is primarily a display of technical virtuoso, with not much interpretative value added (note also, in this respect, that if one takes the assumption of $\varepsilon \rightarrow 0$ as realistic, one must, symmetrically, allow a speed of convergence to the "good" equilibrium which goes to zero).

40 Note also that the infinite-population case, most often formalised through generalised Polya urns (for a survey and applications, cf. Dosi and Kaniovski (1994)), allows a much easier account of dynamic increasing returns. Formally, the latter imply some equivalent to a possibly unboundedly increasing potential function. Conversely, all the finite-population cases we are aware of are driven by some equivalent to an invariant conservation principle. As we see it, learning most often does imply dynamic increasing returns : e.g., even in the most trivial cases, efforts in search, when successful, yield relatively easy replication (and thus near-zero marginal costs). A straightforward implication is that history matters, and increasingly so as the process goes on. The fact that so far, in the finitepopulation cases one must formally rely upon time-invariant Markov processes most often carries due to the formal properties of the model itself - conclusions that the system may fluctuate also in the limit across action patterns (or systems of collective representations). We do not have any problem in accepting the heuristic value of the conclusion under bounded increasing returns (such as those stemming from informational interdipencies on e.g. financial markets), but we have great reservations in the cases when returns to knowledge are in principle unbounded.. 
free public information (possibly with noisy disturbance), while Dosi, Ermoliev and Kaniovski (1994) assume that agents estimate frequencies by observing a sample of the population.

Finally, note that in the models with infinite population no learning takes place at the level of a single agent, as the latter cannot modify its once-and-for-all decision, while in finite population models some primitive form of individual learning does accur as agents modify their actions according some observation of the behaviour of the other agents.

In fact, all this hints at a more general issue, namely the interaction between, so to speak, "the weight of history" and agents' abilities to extract information from it. For example, Arthur and Lane (1993) consider a model of choice between two technologies A and $\mathrm{B}$ with a feedback between past adoptions and choice criteria. The states of the world represent the properties of such technologies $S=\left\{\mathrm{s}_{\mathrm{A}}, \mathrm{s}_{\mathrm{B}}\right\}$ : these are unknown to agents, who only hold prior distributions $\mathrm{N}\left(\mu_{\mathrm{A}}, \sigma_{\mathrm{A}}\right)$ and $\mathrm{N}\left(\mu_{\mathrm{B}}, \sigma_{\mathrm{B}}\right)$. At each time $t$ one agent adopts one of the two technologies by maximising his expected utility :

$$
E\left[U\left(c_{i}\right)\right]=\int U\left(c_{i}\right) \pi\left(c_{i} \mid X\right) d c_{i}
$$

where $\mathrm{U}$ is utility function (with constant risk-aversion) and $\pi\left(c_{i} \mid X\right)$ is the posterior distribution computed as follows. When an agents makes its choice, it samples $\tau$ agents among those who have already chosen. $\mathrm{X}$ is thus a vector of dimension $\tau$, whose components are each single observation in the sample, which is supposed to be drawn from a normal distribution with finite variance :

$$
x_{j}=c_{i}+\varepsilon \quad \varepsilon \approx N\left(0, \sigma^{2}\right)
$$

By applying Bayesian updating agents can compute posterior distributions and choose the technology with higher expected utility.

Interestingly, it can be shown that in these circumstances, notwithstanding the procedural "rationality" of the agents, the dynamics might lead to collective lock-in into the "inferior" option (but, remarkably, in Lane and Vescovini (1996) apparently less "rational" decision rules turn out to be dynamically more efficient from a collective point of view).

Note that this model is equivalent to a learning model with single agent and environmental feed-back : at each time $t$ the agent observes $\tau$ realisations of the states of the world, where the probability that each observation is generated by A or B is initially identical and is then modified through Bayesian updating, but this very learning process will change the distribution from which the agent samples the following time step by producing a feed-back on the states of the world (In this respect, notice incidentally that empirically 
agents tend to display much less procedural rationality than that postulated here, leading to systematic misperception even in simple deterministic environments : cf. Sterman (1989a) and (1989b)).

\section{Models with local learning.}

The class of models illustrated above assume that agents base their actions on some global observation of (or feedback with) the population or a sample thereof. Another perspective describes instead set-ups where agents respond to some local observation of the characteristic of a given subset of the population. Agents only observe their "neighbours" (cf. for instance Kirman (1994), David (1993), and Dalle (1993) and (1994)) defined according to some spatial or socio-economic measure of distance. Let be $d(i, j)$ the distance between agent $i$ and $j$ and be $d^{*}$ a given threshold, the set of agents who are neighbours of agent $i$ is defined as :

$$
\mathrm{V}_{\mathrm{i}}=\left\{\mathrm{j} \in \mathrm{I}: \mathrm{d}(\mathrm{i}, \mathrm{j}) \leq \mathrm{d}^{*}\right\}
$$

If the set $\mathrm{V}_{\mathrm{i}}$ are not mutually disjoint, it is possible that local phenomena of learning and adaptation (i.e. inside a given neighbourhood) spread to the entire population.

One way of modelling this kind of processes is based on Markov fields (e.g. Allen (1982), An and Kiefer (1995), Dalle (1994), Durlauf (1994), Orléan (1990)) assuming that agents stochastically select their actions depending on the actions or "states" of their neighbours. Suppose for instance that payoffs increase in the degrees of coordination with neighbours. Collective outcomes will depend upon the strength of the incentives (as compared to some "internal" motivation of each agent): when incentives are not strong enough, high levels of heterogeneity will persist ; conversely, if premium on coordination is high enough, the system will spend most of its time in states of maximal coordination (though it might keep oscillating between them, cf. Kirman (1993) $)^{41}$.

Another class of models assume that agents choose their action deterministically (cf. Blume (1993) and (1994), Berninghaus and Schwalbe (1992) and (1996), Anderlini and Ianni (1993), Hertz (1994), Nowak and May (1992) and (1993), in ways that are basically isomorphic to simple cellular automata, whereby the state of each agent depends, according to some deterministic rule, on the states of its neighbours.

\footnotetext{
${ }^{41}$ Such results however do not seem to show much robustness with respect to both the algorithm that agents use to choose actions and the size of the population (cf. Follmer (1974) and Hors and Lordon (1995)).
} 
Certainly, having some space which specifies learning mechanisms, in principle conditional on "where a particular agent belongs", is a fruitful development in accounting for heterogeneity and path-dependency in processes of adaptive learning ${ }^{42}$. However, note also that in terms of how learning occurs, a fixed "spatial" structure implies indeed a "structure" - being it on metaphorically geographical, technological or cultural spaces which ought to be phenomenologically justified : on the contrary, it is lamentable to find most often e.g. a two-dimensional lattice, a taurus, etc. being introduced with careless casualness.

In the perspective discussed so far, both stochastic and deterministic models of local learning consider learning as a selection over a fixed menu of actions. However, an alternative interpretation suggest that they could somehow model also processes of learning in the (fixed) space of representations.

Consider $\mathrm{N}$ agents on a bi-dimensional graph who select among $\mathrm{k}$ possible actions, and assume further that :

- the set of states of the world is given by all the Nk possible configurations of the graph (assuming that the action taken by the corresponding agent characterises the state of a node)

agents hold a partial representation of such a set $S$, as they only observe a part of the state of the world, i.e. that given by the state of its neighbours.

An agent's neighbourhood represent a sort of window through which it can only observe a part of the world : thus the agents try to adaptively infer the state of the entire graph from such window observation.

But, given this interpretation, we should expect that learning should involve a progressive "enlargement of the window" so that agents could achieve an ever more complete picture of the world. Some results show that above a threshold of interconnection in the graph all agents globally converge to a state where they implicitly access to all the information available in the system (cf. Bala and Goyal (1993), Hammersley and Welsh (1980), Grimmet (1989)). However, there seem to be no monotonicity in the relation between the "width of the window" and the asymptotic quality of the learning process (holding the nature of interconnections constant, between agents and between the past and the present).

${ }^{42}$ An important limitations of these models is the rigidity with which the structure of the neighbourhood is defined. However, Kirman, Oddou and Weber (1986) and Ioannides (1990) Bala and Goyal (1993) have given a more general formulation, in which the very structure of the graph is modified stochastically. 


\section{Population-level vs. agent-level learning.}

We have already remarked that one way of interpreting standard evolutionary games is in terms of agents who are simple replicators which, individually, do not actually learn anything : only the population does. More sophisticated models (cf. for instance the already mentioned contribution by Young (1993)) take a different route and are also meant to explore some (boundedly rational) cognitive capability of agents, such as some memory of previous events and some simple decision-making algorithms ${ }^{43}$.

But it is clear that, with some modification, these kind of selection based models have an immediate appeal also as models of individual learning: once the population of individuals - each characterised by a single action - has been replaced by a single individual who adaptively learn to select among a set of possible actions at his disposal. Stochastic approximation models of adaptive beliefs try to move in this direction. The basic idea behind these models can be cast in the following way. Suppose that the learning agent has a set of actions $A=\left\{a_{1}, a_{2}, \ldots . ., a_{n}\right\}$; does not know the realisation of the state of the world $\mathrm{s}^{\mathrm{t}}$, but only perceives a realised payoff $\pi^{\mathrm{t}}$. In this case a rational Bayesian decision maker should form prior beliefs on all the possible payoff matrices. An adaptive learner instead randomly chooses among actions according to some strength which he attaches to actions. Let us call $F_{k}^{t}$ the strength assigned to action $a_{\mathrm{k}}$ at time t. The strength is updated according, say, to the rule :

$$
F_{k}^{t+1}=F_{k}^{t} \frac{f^{k}\left(\pi^{t}\left(s^{t}, a_{k}\right)\right)}{\sum_{k} f^{k}\left(\pi^{t}\left(s^{t}, a_{k}\right)\right)}
$$

Actions are randomly selected at $\mathrm{t}$ with probabilities given by

$$
P^{t}\left(a_{k}\right)=\frac{F_{k}^{t}}{\sum_{i} F_{i}^{t}}
$$

This selection mechanism induces a stochastic process on the strengths assigned to competing rules whose asymptotic behaviour can be studied.

This and similar selection mechanisms can be found, for instance, in Arthur (1993), Posch (1994), Easley and Rustichini (1995), Fudenberg and Levine (1995), Marimon and McGrattan (1995). Easley and Rustichini's model, in particular, provides a neat connection between population-level and individual-level evolutionary arguments. In their model, Easley and Rustichini consider an individual decision maker facing an unknown 
environment represented by a stochastic variable. Instead of forming beliefs on the set of possible processes and updating them according to the Bayesian approach, he adaptively selects among a set of behavioural rules $\Re$ (of the same kind of our basic model) according to a strength updating rule of the kind of expression (6) and a random selection rule of the kind of expression (7). This enables them to study the stochastic process induced on the strengths of rule $r_{i}$, which is given by the expression :

$$
F_{k}^{t+1}=\prod_{z=0}^{t} F_{k}^{z} \frac{f^{k}\left(\pi^{z}\left(s^{t}, a_{k}^{t}\right)\right)}{\sum_{k} f^{k}\left(\pi^{z}\left(s^{t}, a_{k}^{t}\right)\right)}
$$

With some further assumptions on the characteristics of the underlying stochastic process on the states of the world (stationarity and ergodicity) and on the selection dynamics (monotonicity, symmetry and independence) they are able to prove that an individual who uses this kind of adaptive selection dynamics eventually acts as if it was an objective expected utility maximiser and, moreover, that the set of rules which are selected by such dynamics corresponds to the set of rules which would be selected by a replicator dynamics.

Some considerations on the importance and limitations of these kinds of models are in order. First of all, note that these approaches end up being pure adaptation/selection models. It is indeed an encouraging result that such simple selection mechanisms are a some times (but not always) able to select behavioural rules which mimic optimising behaviour prescribed by normative theories, but of course a necessary (and highly demanding) condition for such behaviour to be selected is that it is there in the first place. Populations must contain optimising individual in order to have them selected by replication mechanisms of selection. On the same token, rules which mimic expected utility maximising behaviour must be in the decision maker's endowment of behavioural rules in order to have them asymptotically selected by the strength updating process. One could say that, by moving from standard models of optimising behaviour to stochastic models of adaptive learning, one moves from a world where agents are assumed to be naturally endowed with the correct model of the world, to a world where agents are endowed with the correct behavioural rules (which define an implicit model of the world), but these are mixed together with incorrect ones and have to adaptively emerge. It is clear that the latter assumption amounts to assuming away the cognitive problem of how such rules are formed and modified. In complex and changing environments in particular, it seems a rather farfetched assumption to start with. In fact stationarity in the underlying selection

\footnotetext{
${ }^{43}$ A further step towards models of agent-level learning could be introduced by labelling agents (cf. the models with local learning presented below).
} 
environment, is a fair approximation whenever one can reasonably assume that the speed of convergence to given fundamentals is of order of magnitude faster than the rate of change in the fundamentals themselves. Ergodicity comes here as a handy auxiliary property : if it does not hold much more detail is needed on initial conditions and adjustment processes.

Relatedly, an important question concerns how long the selection process takes to select good rules ${ }^{44}$.

Second, and again related to the previous points, as in Easley and Rustichini (1995) suppose that, at each stage of the adaptive learning process, the strength of all rules is updated according to the payoff they would have received in the realised state of the world. This assumption is justified if and only if the learning agent's actions do not determine any feed-back on the environment and if and only if the agent knows it. When this is not the case, only the strength of the actually employed rule can be updated and therefore lock-in phenomena and non-ergodicity may well emerge : exploitation vs. exploration and multiarmed-bandit type dilemmas are unavoidable.

These quite fundamental questions in fact hints at some general issues, a fortiori emerging in fully fledged evolutionary environments. And, indeed a theoretical in order to explore them is based on so-called Artificially Adaptive Agents, which are briefly examined in the next section.

\section{Artificially Adaptive Agents.}

If we drop the assumption that agents are naturally endowed with the correct model of the environment in which they operate, the fundamental topic of inquiry becomes how models and representations of the world are generated, stored and modified by economic agents. On the one hand, as we have already argued, this consideration carries the requirement for some form of cognitive and psychological grounding. On the other hand it opens new possibilities for applications to economics of families of models developed in Artificial Intelligence, and especially in that branch of AI which considers selection and variation mechanisms as a basic driving force for learning.

The main point of interest in this kind of models is that the dynamics involved is essentially open-ended, both when the object of the modelling exercise is the dynamics of

${ }^{44}$ Some considerations on this problem can be found in Arthur (1993), who argues that the speed of convergence is highly sensitive to the variance of payoffs associated to different actions. Of course the longer the convergence process, the more implausible appears the assumption of stationarity of the environment. 
multi-agent interactions and when instead modelling concerns individual learning (for a general overview on the AAA perspective in economics see, for instance, Arthur (1993) and Lane (1993a) and (1993b) $)^{45}$.

Open-ended dynamics is a consequence of two strong theoretical commitments of the AAA perspective. Firstly, AAA models are not restricted to pure selection dynamics, but consider the introduction of novelty, innovation, generation of new patterns of behaviour as a basic force for learning and adaptation. Thus the dynamics never really settles into equilibrium states.

Second, the AAA perspective considers heterogeneity among agents and complexity of interaction patterns (among agents in models of collective interaction, among behavioural rules in models of individual learning) as crucial aspects of the modelling exercise. In fact, in the AAA approach heterogeneity among agents (in terms of representations, expectations, learning paths) is the norm and homogeneity the exception : therefore seemingly persistent equilibria tend to be in fact transient states of temporary "ecological" stability, where small variation can trigger non linear self-reinforcing effects.

An interesting prototypical example of AAA can be found in Lindgren (1991). He considers a classical repeated prisoner's dilemma played by a given population of players. Each agent is defined by a strategy, which deterministically maps finite-lengths histories of the game (here represented by sequences of Defeat or Cooperate actions performed by the player itself and his opponent) into an action (Defect or Cooperate). This population is then processed via an extended genetic algorithm which allows for variable length genomes. Simply allowing for strategies based on variable length histories makes the number of possible species in the population practically infinite and the search space unlimited. Hence, evolution is no longer a selection path in a finite and closed space of alternatives, but "[.......] can then be viewed as a transient phenomenon in a potentially infinite-dimensional dynamical system. If the transients continue forever, we have open-ended evolution" (Lindgren (1991), p. 296, emphasis in original).

The dimension and complexity of strategies becomes itself one of the elements subject to evolutionary selection and variation. This perspective enriches the concept of strategy implicit in the standard evolutionary game framework. While in the latter "strategy" is most often squeezed down to an action taken from a given set of possibilities, in AAA models, it is easy to account for evolving "strategies" made up by changing combinations of

45 All this, notwithstanding the spreading practice of using AAA models to show adaptive convergence to conventional equilibria (often characterised by seemingly "rational" forward-looking behaviours at the equilibrium itself). Of course we do not deny that sometimes adaptive AAA learning might lead there. However, we consider the epistemological commitment to the search of those 
a set of basic operators, categories, variables. (However, what is still missing in AAA models is the possibility to model learning as a modification of this set of basic operators, variables, detectors of environmental states, unless they originate from some combination of the elementary ones with which the system is initially endowed). In terms of our earlier basic model, this difference amounts to an explicit search process regarding the algorithm mapping "internal" representations to action patterns (in the case of AAA models), as compared to its "black-boxing" into adaptive selection of actions themselves (in the case of most evolutionary games).

This distinction is even clearer in more explicitly rule-based AAA models.

Rule-based AAA models differ from the stochastic models outlined in the previous section at least in two fundamental respects. They consider learning as the joint outcome of the processes of generation, replication, selection and modification of behavioural rules. As the space of behavioural rules is potentially unlimited - even in relatively simple problems and the very search space is ill-defined and subject to change, the generation of new rules, new representations and new actions is an essential mechanism for learning and adaptation.

The second aspect, related to the previous one, is that, except in very simple problems nested in stationary environments, the outcome of the learning process cannot be constrained to be a single behavioural rule, but may be a whole "ecological" system of rules which together form a representation of the environment (on the so-called "computational ecologies" see also Huberman amd Hogg (1995)). Behavioural patterns which emerge in AAA models may therefore be much richer than those predicted by pure selection models. Here, learning takes explicitly place in both spaces of representations/models of the world and action repertoires ${ }^{46}$.

A prototypical example of rule-based learning models is represented by the so-called Classifiers Systems (cf. Holland (1986), Holland et al. (1986), for an overview of actual and possible applications to economics Arthur (1991) and (1993) and Lane (1993b), for some specific applications Marimon, McGrattan and Sargent (1990), Marengo (1992), Marengo and Tordjman (1996), for a survey see also Hoffmeister and Bäck (1991)).

Learning in Classifiers Systems presents the following general features :

1. learning takes place in the space of representations. In a complex and ever changing world agents must define sets of states which they consider as equivalent

adaptive processes displaying such limit properties (often at the cost also of ad hoc rigging of the learning assumptions) as a somewhat perverse use of AAA modelling techniques.

${ }^{46}$ In this respect, a particularly interesting question concerns the circumstances under which simple behavioural patterns do emerge notwithstanding the potential cognitive complexity which these models entail. In Dosi et al. (1995) we show that this is often the case in the presence of competence gaps of the agent vis-à-vis the complexity of the changing environment (see also below). 
for the purpose of action. In other words, they have to build representations of the world in order to discover regularities which can be exploited by their actions. These representations have a pragmatic nature and are contingent upon the particular purpose the routine is serving.

2. learning must be driven by the search for better performance. Learning agents must therefore use some system of performance assessment.

3. if rules of behaviour have to be selected, added, modified and discarded, there must exist a procedure for the evaluation of the usefulness of rules. This problem might not have a clear solution when the performance of the system may be assessed only as a result of a long and complex sequence of interdependent rules (such as in the game of chess, for instance).

Let us consider again the basic model of decision making introduced above and suppose that it is faced repeatedly by the same agent. The decision maker, by using its experience of the previous stages of the game, makes a forecast of the state of the world which will occur next and chooses an action which he or she considers as appropriate. At the outset the player has no knowledge either of the payoff matrix or of the "laws" which determine the changes in the environment. The decision process consists therefore of two elements : the state of knowledge about the environment, represented by the agent's forecasting capabilities, and the rules for choosing an action, given this forecast.

In its most basic formulation, a Classifier System is a set condition-action rules which are processed in parallel. Each rules makes the execution of a certain action conditional upon the agent's perception of a certain state of the world.

A first element which characterises a classifier system is the message (signal) the learning agents receives from the environment. Such a message has to be interpreted and connected to a consequent action according to a model of the world which is subject to revisions. The signal is usually encoded as a binary string of given length :

$$
\mathrm{m}_{1} \mathrm{~m}_{2} \ldots . . \mathrm{m}_{\mathrm{n}} \quad \text { with } \mathrm{m}_{\mathrm{i}} \in\{0,1\}
$$

The learning is modelled as a set of condition-action rules which are processed in a parallel fashion. Each rule makes a particular action conditional upon the fulfilment of a condition concerning the present state of the world. The condition part is therefore actually made up of a string of the same length as the message's, which encode a subset of the states of nature and is activated when the last detected state of the world falls into such a subset : 


$$
\mathrm{c}_{1} \mathrm{c}_{2} \ldots . . \mathrm{c}_{\mathrm{n}}
$$

with $c_{i} \in\{0,1, \#\}$

The condition is satisfied when, either $c_{i}=m_{i}$ or $c_{i}=\#$; i.e. the symbol \# acts as a "don't care" symbol which does not pose any constraint on the corresponding bit of the environmental message.

Thus, consistently with the framework discussed in the previous section, a set of conditions defines a subset of the power set of S. It is important to notice that each condition defines one subjective state of the world, as perceived by the agent and defines its relationship with the objective states of the world. This relationship remains anyway unknown to the decision maker, who "knows" only the subjective states.

The action part is instead a string of length $\mathrm{p}$ (the number of the agent's possible actions) over some alphabet (usually a binary one) which encodes possible actions :

$$
a_{1} a_{2} \ldots a_{p} \quad \text { with } a_{i} \in\{0,1\}
$$

The decision maker can be therefore represented by a set of such conditionaction rules :

$$
\begin{gathered}
\mathrm{R}=\left\{\mathrm{R}_{1}, \mathrm{R}_{2}, \ldots . . \mathrm{R}_{\mathrm{q}}\right\} \\
\text { where }: \\
\mathrm{R}_{\mathrm{i}}: \mathrm{c}_{1} \mathrm{c}_{2} \ldots \mathrm{c}_{\mathrm{n}} \rightarrow \mathrm{a}_{1} \mathrm{a}_{2} \cdots \mathrm{a}_{\mathrm{p}} \quad \text { with } \mathrm{c}_{\mathrm{i}} \in\{0,1, \#\} \text { and } \mathrm{a}_{\mathrm{i}} \in\{0,1\}
\end{gathered}
$$

In addition each rule is assigned a "strength" and a "specificity" (or its reciprocal "generality") measure. The strength basically measures the past usefulness of the rule, that is the payoffs cumulated every time the rule has been applied (minus other quantities which will be specified later); the specificity measures the strictness of the condition : the highest specificity (or lowest generality) value is given to a rule whose condition does not have nay symbol "\#” and therefore is satisfied only when that particular state of the world occurs, whereas the lowest specificity (or the highest generality) is given to a rule whose condition is entirely formed by "\#' $s$ " and is therefore always satisfied by the occurrence of any state of the world.

At the beginning of each simulation the decision maker is usually supposed to be absolutely ignorant about the characteristics of the environment : thus all the rules are initially randomly generated. 
The decision maker is also assumed to have limited computational capabilities, therefore the number of rules stored in the system at each moment is kept constant and relatively "small" in comparison to the complexity of the problem which is being tackled.

This set of rules is processed in the following steps throughout the simulation process :

1. Condition matching: a message is received from the environment which informs the system about the last state of the world. Such message is compared with the condition of all the rules and the rules which are matched, i.e. those which apply to such a state of the world enter the following step.

2. Competition among matched rules: all the rules whose condition is satisfied compete in order to designate the one which is allowed to execute its action. To enter this competition each rule makes a bid based on its strength and on its specificity. In other words, the bid of each matched rule is proportional to its past usefulness (strength) and its relevance to the present situation (specificity) :

$$
\begin{gathered}
\operatorname{Bid}\left(\mathrm{R}_{\mathrm{i}}, \mathrm{t}\right)=\mathrm{k}_{1}\left(\mathrm{k}_{2}+\mathrm{k}_{3} \operatorname{Specificity}\left(\mathrm{R}_{\mathrm{i}}\right)\right) \operatorname{Strength}\left(\mathrm{R}_{\mathrm{i}}, \mathrm{t}\right) \\
\text { Where } \mathrm{k}_{1}, \mathrm{k}_{2} \text { and } \mathrm{k}_{3} \text { are constant coefficients. }
\end{gathered}
$$

The winning rule is chosen randomly, with probabilities proportional to such bids.

3. Action and strength updating: the winning rule executes the action indicated by its action part and has its own strength reduced by the amount of the bid and increased by the payoff that the action receives, given the occurrence of the "real" state of the world. If the $j$-th rule is the winner of the competition, we have :

$$
\operatorname{Strength}\left(R_{j}, t+1\right)=\operatorname{Strength}\left(R_{j}, t\right)+\operatorname{Payoff}(t)-\operatorname{Bid}\left(R_{j}, t\right)
$$

4. Generation of new rules: the system must be able not only to select the most successful rules, but also to discover new ones. This is ensured by applying "genetic operators" which, by recombining and mutating elements of the already existing and most successful rules, introduce new ones which could improve the performance of the system. In this way new rules are constantly injected into the system and scope for new search is always made available.

Genetic operators generate new rules which both recombine "building blocks" of, and, explore other possibilities in the proximity of the presently most successful ones, in order to discover the elements which determine their success and exploit them more thoroughly: the search is not completely random but influenced by the system's past 
history. New rules so generated substitute the weakest ones, so that the total number of rules is kept constant.

Three types of genetic operators are normally employed. The first two types are forms of simple mutation which operate in opposite directions :

a) Specification: a new condition is created which increases the specificity of the parent one : wherever the parent condition presents a "\#”, this is mutated into a "0" or a "1" (randomly chosen) with a given (small) probability.

b) Generalisation: the new condition decreases the specificity of the parent one : wherever the latter presents a " 0 " or a " 1 ", this is mutated into a "\#” with a given (small) probability.

The third operator is a standard crossover, which reflects the idea of generating new conditions by recombining useful elements ("building blocks") of the conditions of successful rules. Two parent rules are probabilistically selected among the ones with higher strength, then a random crossover point is selected for each condition part and strings are exchanged across such crossover points.

If, for instance, the conditions of the two parent rules' are :

aaaaaa

\section{AAAAAA}

with a, $A \in\{0,1, \#\}$

if 2 is randomly drawn as crossover point, the two following offsprings are generated :

$$
\text { aaAAAA }
$$

Aaaaaa

The above mentioned economic models which employ classifiers systems for the analysis of multi-agent interaction problem, basically study the emergence of "ecologies of representations". Heterogeneous agents adaptively modify their models of the world in order to achieve better performance, and stationary environments tend to generate relatively stable ecological equilibria, but, in general, agents will not converge to homogeneous models, but only to models which are somehow "compatible" for the particular states of the world which actually occur. The same environment can in fact support very diverse non-partitional representations : stochastic elements in the learning process, combined with the high degree 
of path-dependency of the systems, will very likely produce a high degree of diversity of representations even when we begin with perfectly homogeneous agents. Moreover, learning never actually stops and the application of the genetic algorithm always introduce an element of exploration of new possibilities which might disrupt the temporary ecological equilibrium.

Marengo (1992) and (1996) applies this model to the emergence of a commonly shared knowledge basis in team decision making processes, and shows that different types of environment can generate very different balances between homogeneity and heterogeneity of knowledge. Palmer et al. (1996), Vriend (1996) and Marengo and Tordjman (1996) examine a population of rule-based AAA operating in an artificial markets and show that the market can sustain persistently high degree of diversity between agents' models of the world and generate at the same time a price dynamics which has many features in common with real speculation markets phenomena.

A slightly different modelling strategy, albeit very much in the same spirit, employs Genetic Programming (Koza (1993)) : unlike standard genetic algorithms and classifiers systems, search does not take place in the space of fixed-length binary string representations, but in the space of all variable length functions which can be generated with a given primitive set of operators and operands. Representations here are no longer mere sets of subsets of subjective states of the world, but are more complex functional relationships which link variables to actions by means of mathematical and logical operators. Dosi, Marengo, Bassanini and Valente (1994) show an application of this methodology to pricing decisions by firms in oligopolistic markets ${ }^{47}$.

In general, these models produce simulations of Artificial Economies (in parallel with the "Artificial Life" approach, cf. Langton (1989), Langton et al. (1991)), in which the analysis is no longer based on equilibrium concepts and on the search for convergence and stability conditions, but on the investigation of collective emergent properties, i.e. aggregate regularities which are relatively robust and persistent (cf. Lane (1993a) and (1993b)).

An interesting family of Artificial Economies models analyses local learning phenomena. For instance, Axtell and Epstein (1994) consider a population of agents located on a bi-dimensional space where some resources (e.g. food) are also (unevenly) distributed. Agents are endowed with a set of simple algorithms which control their movements, their use of available resources, their behaviour towards other agents they can meet. Adaptation takes place at two different levels : a) with respect to the environment agents move towards sites where they more easily fulfil their objectives ; b) with respect to their neighbours, they

47 In particular, it has been shown there the endogenous emergence of pricing routines as an evolutionary robust form of adaptation to non-stationary environments. 
generate local organisation of exchange (i.e. markets where they can exchange goods and achieve Pareto-superior distribution of resources). Take all this as a preliminary metaphor of a set of models still to come where propositions of economic theory (e.g. downward sloping demand curves, laws of one price, etc.) could be derived as emergent properties of decentralised interaction processes.

\section{Learning as dynamics in the space of outcomes.}

The typologies of learning models review so far attempt, to different degrees, to provide some account of the dynamics of e.g. what agents know about the world, or the ways people select among different actions, etc.

Alternative modelling strategies involve, on the contrary, an explicit black-boxing of the learning/decision processes, folding them together into some dynamics on the possible states in which the agents might happen to be. In turn, this "black-boxing" in some approaches has to be considered as just a reduced form of an underlying richer dynamics on cognition, problem-solving ,etc., while in others tends to be considered almost all that can be said about learning.

The latter perspective certainly applies to a long tradition of formal models in psychology building on stimulus-response processes, dating back at least to Estes (1950) and Bush and Mosteller (1955). (Note that insofar as the "states", - through which the agents are driven by reinforcement -, are behavioural responses, this modelling philosophy largely overlaps with that of "evolutionary games", briefly discussed earlier).

A good summary of the basic ideas is from Suppes (1995) :

\footnotetext{
"The organism is presented with a sequence of trials, on each of which he makes a response, that is one of several possible choices. In any particular experiment it is assumed that there is a set of stimuli from which the organism draws a sample at the beginning of each trial. It is also assumed that on each trial each stimulus is conditioned to at most one response. The probability of making a given response on any trial is postulated to be simply the proportion of sampled stimuli conditioned on that response, unless there is no conditioned stimuli in the sample, in which case there is a "guessing" probability for each response. Learning takes place in the following way. At the end of the trial a reinforcement event occurs that identifies which one of the possible response was correct. With some fixed probabilities the sample stimuli become conditioned to this response, if they are not already, and the organism begins another trial in a new state of conditioning... (Suppes (1995), p. 5).
} 
Notice that here all dynamics on $\Theta, \Xi, R$, and $\pi$ one was trying to disentangle above are black-boxed into the distribution of stimuli and the conditional probabilities of transition across responses.

A simple illustration (Suppes (1995)) with two states, one conditioned to the correct response ( $\mathrm{C}$ ) and the other unconditioned $(\mathrm{U})$ is a Markov process of the type

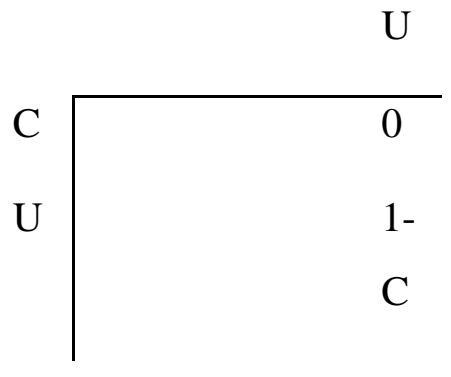

with the elements of the matrix being the transition probabilities. Not too surprising, "learning is the convergence to the absorbing state".

Moreover, notice that the basic methodology requires an underlying "small"/stationary world assumption (all states must have from the start a positive probability measure) and is essentially looking for asymptotic properties of the models ${ }^{48}$.

\section{Technological learning.}

Nearer to the spirit of a good deal of contemporary evolutionary theories, a quite different type of "black-boxing" is common to a lot of models of growth and industrial change driven by technological advances. Here the learning dynamics is typically represented in terms of changes in the space of some technological coefficients.

\footnotetext{
${ }^{48}$ It is true that in some simple experimental set-ups stimulus-response models generate also predictions on the convergence paths. But this is not the case in general, especially outside the domains whereby stimulus sampling and conditioning can be given a straightforward psychological interpretation (representation-building and problem-solving are two cases to the point). So, for example, one is left to wonder what is the empirical content of the "main theorem", from Suppes (1969) (see also (1995)) according to which "given any finite automaton, there is a stimulus-response model that under appropriate learning conditions asymptotically becomes isomorphic to the finite automaton".

One is very far indeed from any constructive, empirically disciplined, notion of learning...
} 
Possibly the simplest formalisation is the early account by Arrow (1962) of learningby-doing, since then corroborated by a few empirical studies, showing a "quasi-law" of falling costs (or increasing productivity) as a function of cumulated production ${ }^{49}$.

In Silverberg, Dosi and Orsenigo (1988), learning how to efficiently use a new capital embodied technology (i.e. a new "paradigm" : see above) is formalised via a logistic-type dynamics on firm-specific skills $\left(\mathrm{s}_{\mathrm{i}}\right)$, dependent on current and cumulated production using the new technology

$$
\begin{array}{cc}
\left(\mathrm{x}_{\mathrm{i}} \text { and } \mathrm{X}_{\mathrm{i}}, \text { respectively }\right): & \\
s_{i}^{\prime}=B_{1} \frac{x_{i}}{X_{i}+C} s_{i}\left(1-s_{i}\right) & \text { if } s_{i} \geq s_{p} \\
s_{i}=s_{p} & \text { otherwise }
\end{array}
$$

where $s_{i}^{\prime}$ is he time derivative, $\mathrm{C}$ is a constant proportional to the capital stock and $\mathrm{sp}$ is the level of skills generally available in the industry, which is a sort of dynamic, industrywide, externality changing as

$$
s_{p}^{\prime}=B_{2}\left(\bar{s}-s_{p}\right)
$$

with $\bar{s}$ a weighted average of firm-specific skills ${ }^{50}$.

Further, many evolutionary models starting from the seminal work of Nelson and Winter (1982), explicitly account for the uncertainty associated with technical search, and often, also for the dependence of future discoveries upon the knowledge already achieved in the past.

In the last resort, modelling learning in the technology space comes down to specification of the stochastic process driving agents from one technique to the next.

For example, in one of the models presented in Nelson and Winter (1982), learning occurs in the space of two variable input coefficients a 1 and a2. After some renormalisation ${ }^{51}$, assume that the technique of each firm at time $t$ is the random pair $U_{t}, V_{t}$ and the search outcome is represented by the random pair $\left(\mathrm{G}_{t}, \mathrm{H}_{\mathrm{t}}\right)$ which capture the number of steps that

\footnotetext{
${ }^{49}$ Something like

$c_{\mathrm{t}}=\mathrm{c}_{\mathrm{o}} \mathrm{X}_{\mathrm{t}}{ }^{\beta}$, the cumulated production, $=\Sigma_{\mathrm{t}} \mathrm{x}_{\mathrm{t}} ;-1<\beta<\mathrm{o} ;$ and $\mathrm{c}=$ unit production costs

${ }^{50}$ Of course, $s$; and $s_{p}$ are bounded to be less or equal to one (i.e. the "perfect" ability to fully exploit the technical specifications of use on any one given vintage of capital).

Somewhat more complicated learning patterns, modelled in a similar spirit, are in Eliasson (1985).

A "Verdoorn-Kaldor" law, with learning driven by learning-by-doing and economics of scale underpins the model by Verspagen (1993). And system-level deterministic learning dynamics is presented in Granstrand (1994b).

${ }^{51}$ So that the refined dimensions are $\mathrm{U}=\log \left(\mathrm{a}_{2} / \mathrm{a}_{1}\right)$ and $\mathrm{V}=\log \left(\mathrm{a}_{1} \mathrm{a}_{2}\right)$.
} 
the firm takes in the $\mathrm{U}$ and $\mathrm{V}$ dimensions ${ }^{52}$, with $\left(\mathrm{G}_{\mathrm{t}}, \mathrm{H}_{\mathrm{t}}\right)$ - in the simplest formulation, independent of $\left(U_{t, 1}, V_{t, 1}\right)$ - distributed on a finite support (Nelson and Winter (1982), pp. 177-9). The time-independent random process, together with a selection criterion simply comparing $\left(\mathrm{U}_{\mathrm{t}, 1}, \mathrm{~V}_{\mathrm{t}, 1}\right)$ and $\left(\mathrm{U}_{\mathrm{t}}, \mathrm{V}_{\mathrm{t}}\right)$ at prevailing input prices, implies that the sequence of techniques is a Markov chain ${ }^{53}$. The distribution of innovative outcomes is centred on the prevailing productivity of a firm and, in the more general formulation, there is no exogenous constraint on technological possibilities (Nelson and Winter (1982), p. 285), although there is one related to internal capabilities : what one knows limits what one can achieve within a given number of search periods.

Other representations in a similar spirit include Silverberg and Lehnart (1994) whereby innovations arrive according to a Poisson distribution, adding to the productivity of new technological vintages of equipment ; Chiaromonte and Dosi (1993), and Chiaromonte et al. (1993) which have the support of the probability distributions on (labour) coefficients for "machine" production and machine-use dependent on time $\mathrm{T}$ realisations for each firm ; Dosi et al. (1994 a) and (1995), who model the dynamics of (proportional) increments in firm "competitiveness" drawn from different variants of a Poisson process ; Kwasnicki (1996) who presents more complex dynamics of search driven also recombination and mutation on incumbent knowledge bases (see also below).

In other versions of evolutionary models, one assumes an exogenously determined drift in learning opportunities (a metaphor for scientific advances, etc.). For example, in another model presented in Nelson and Winter (1982), firms sample from a log - normal distribution of values of capital productivities whose increasing mean follows a time dependent trend. And somewhat similarly, Conlisk (1989) postulate productivity growth driven by draws from a normal distribution (with positive mean).

Finally a few evolutionary models account also for learning via imitation, that is by the stochastic access of each firm to the best practice available at each time or to the set of combinations between best practice and the technique currently known by any generic incumbent (cf. Nelson and Winter (1982), Chiaromonte et al. (1993), Silverberg and Verspagen (1994) and (1995a), Kwasnicki (1996), among others).

\footnotetext{
${ }^{52}$ Subject to the constraint that $\mathrm{u}_{1} \leq \mathrm{U} \leq \mathrm{u}_{\mathrm{n}}$. Conversely, $\mathrm{V}$, itself a proxy for input productivity, in the spirit of evolutionary models, is allowed to range on $-\propto<\mathrm{V}<+\propto$.

${ }^{53}$ (cf. Nelson and Winter (1982) pp. 179-92). Note also that in this Nelson - Winter model, while in terms of relative input intensities the process define a finite, time-invariant, Markov process, in the $\mathrm{V}$ dimension the number of states is notionally infinite and the system is allowed, so to speak, to climb to
} 
First, note that the spirit of most formalisations of learning processes in a technology space, however defined, has an essential "phenomenological" flavour: formal representations are meant to capture stylised facts, basic dynamic regularities, etc. generally placed at a much "higher" (and more aggregate) level of description than the "foundational" processes of cognition, problem-solving, etc. discussed earlier (on the relationships between the two levels we shall come back in a moment). Given this more phenomenological level, however, a requirement far from fulfilled in the current state-of-the-art concerns the empirical robustness of the purported dynamics ${ }^{54}$ : for example, on which empirical grounds does one justify the assumption of Poisson arrival processes ? Why not another random process? On what criteria does one choose the specification of the Markov processes driving search ?, etc.

This is an area where evolutionary modellers would certainly benefit from more precise insights coming from "inductive" statistical exercises concerning e.g. microeconomic processes of innovation, productivity growth, etc.

Second, even when considering learning over an upper-bounded set of "knowledge states" (such as in Silverberg et al. (1988)), and, obviously so in open-ended knowledge dynamics, the analytical focus is upon transient rather than limit properties.

An example in the set-up concerning innovation-diffusion and learning-by-using on two technologies is presented in Silverberg et al. (1988). The properties of limit states could in principle be found, given initial conditions, etc. However, the attention is mainly devoted to the finite-time properties of the system and the finite-time learning profile of individual agents.

A fortiori, all this applies to learning dynamics which are open ended in the sense that there is an infinite number of states that agents can take as time goes to infinity, even if, most likely, conditional on given knowledge level, only a finite number of states can be reached with positive probability in a finite time ${ }^{55}$.

Third, it seems to us rather straightforward that any representation of learning as a dynamics across technological (or for that matter "organisational") states in low dimensional spaces is just an inevitable (indeed, very useful) reduced form of underlying learning process in spaces of explosively high dimensionality (as those entailed by the earlier, more

ever greater levels of productivity (although only finite levels of them are accessible from a given state).

${ }^{54}$ And this should be indeed a self-criticism of all of us who have been working on evolutionary modelling...

${ }^{55} \mathrm{~A}$ major analytical challenge ahead regards in fact the possibility of characterising in the limit some expected (average) properties of these open-ended processes ( - an ongoing research involving S. Winter, Y. Kaniovski and the authors at IIASA, Austria, is currently beginning to painstakingly address the problem...). 
"constructive" discussion of exploration on cognitive and problem-solving categories... ${ }^{56}$ ). But then the question of the compatibility and mappings across different levels of description becomes crucial (let alone a direct derivation "higher" from "lower" levels, which might well turn out to be an impossible task without a lot of further phenomenological details and constraints : cf. our earlier "parable of the cow"...).

\section{Behavioural and cognitive foundations of technological learning.}

Of course, the easiest way to provide cognitive/behavioural foundations to learning in the technology space is by assuming that it is the direct outcome of the choices of fully rational (and forward looking) agents. This is, indeed, the path followed by "New Growth" theories - if their micro-foundations are to be taken at face value -. (cf. Romer(1990), Grossman and Helpman (1981), or, in a stochastic version, Aghion and Howitt (1992) ${ }^{57}$.

However, if one accepts the foregoing argument, fully 'rational' decision models fall well short of applicability to technological search and innovation : on the contrary, this is the domain where one is most likely to find strong substantive and procedural uncertainty, surprises, delusions and unexpected successes (for a review of the empirical evidence in this area, see Dosi (1988)). But then one is back to the relationships between a phenomenological account of learning processes and the underlying cognitive and behavioural procedures...

In this respect, Nelson and Winter(1982) suggest a promising appreciative theory, nesting technological learning (and some of its properties, such as the possible cumulativeness of technological advances, the 'locality' of search, etc.) into a theory of organisational learning, based - in a good part - on the establishment, reproduction and change of organisational routines.

Moreover, Nelson-Winter, - as well as, earlier, the inspiring work of Cyert and March (1963), and later, many models in this evolutionary tradition - formally model the 'access' to change as being triggered or driven by some stylised decision rule.

\footnotetext{
${ }^{56}$ Collective learning entities such as "firms" further explode the space of search/adaptation...

${ }^{57}$ This equally applies to e.g. game-theoretic models of innovation and diffusion, "patent races", etc. (thorough surveys are in Stoneman (1995)).

Whether such microfoundations ought to be taken seriously is a debatable question. The more sophisticated view suggests that they should not - forward looking representative agents, etc. being only a sort of theoretical shortcut in order to get to some some aggregate dynamic properties which $a$ fortiori hold under less restrictive behavioural assumptions ( a lot of contributions of e.g. Paul Romer , and , in other perspectives, Joseph Stiglitz, and others are interpretable in this way). On the contrary,
} 
A way of capturing this bridge between the behavioural domain and an apparently "agent-free" learning dynamics is by assuming some sort of rather simple allocation-tosearch rule (such as “.. invest $x \%$ of turnover in $R \& D$..") - which are indeed robustly corroborated by the managerial evidence - , and then formalise a probability of access to innovative (or imitative) learning dependent on these search efforts.

A binomial distribution of the kind

$$
\mathrm{P}(\mathrm{inn}=1)=\mathrm{a} * \exp (\mathrm{b} * \mathrm{R} \& \mathrm{D})
$$

is a first approximation to the general idea (with $\mathrm{a}$ and $\mathrm{b}$ being parameters which implicit account for both 'objective' opportunities and firm-specific competencies)(Cf. e.g. Nelson and Winter(1982), Chiaromonte et al.(1993)). ${ }^{58}$

Hence the learning dynamics is modelled as the outcome of a two-stages stochastic process, separating a first ('behavioural') process depending, in principle, on believes, expectations, and action patterns (that is the $\vartheta$ 's and $\xi$ 's variables - in our erlier formulation - ), and a second one, trying to capture some modal properties of the learning process itself $f^{59}$.

Other formalisations of the interactions between behaviours and learning modes stylise "triggering effects", so that for example, change and search is undertaken only if actual performance falls below a certain threshold level ${ }^{60}$.

For many analytical purposes, the assumption that behavioural rules (such as R\&Drules) are given and invariant throughout the history of each agent is a perfectly legitimate approximation (which captures also the relative inertia of organisational routines ..).And this is what one finds in many evolutionary models up to now.

In fact, invariant search rules (or invariant 'meta-rules' for change) can be understood in two ways, namely (a) as empirically-grounded 'stylised facts', or, (b) as useful firstapproximation assumptions whose precise status has to be understood also in terms of complementary processes of behavioural learning. They certainly capture a bit of both : but, in order to move further at the former level it is urgent to achieve more robust micro-

the conclusions of too many other models seem to be sensitively dependent upon the fine specifications of 'rational behaviours' themselves .

${ }_{58}^{58}$ And the same goes for imitation.

${ }^{59}$ Which, putting it into our earlier formalisation, would be a synthetic account of externally evaluated (or 'market-evaluated') performances of the combinations between menus of actions and 'states of the world'. It is also important to notice that the general assumption here is that agents do not and cannot know that mapping algorithm.

${ }^{60}$ Cf. Nelson and Winter(1982), and also outside the technological domain Cyert and March(1963). 
behavioural evidence ${ }^{61}$, and, at, the latter level, to show if and how endogenous process of adaptation lead to relatively persistent (meta-stable )search rules. This latter analysis is what Silverberg and Verspagen (1995b) have begun to do, assuming rules that are invariant as such, but whose parameters may adaptively change via a stochastic search process ( with different modelling tools based on genetic algorithms Kwasnicki (1996) explores a similar path).

Alternatively, one might want to take a more constructive route to behavioural search and adaptation, but, so far, at the cost of further simplifying the environment in which agents operate (an example is Dosi et al.(1994),where "routines" like mark-up pricing are indeed shown, as already mentioned to be endogenous emergent properties but one totally neglects learning in the technology/problem-solving domain).

More generally, technological learning is possibly one of most revealing points of observations in order to assess the state-of-the-art in the theories of learning in evolutionary environments. Hopefully, there should be little doubt that technologies (together with organisational forms and institutions) are major domains of economic evolution. Technical change is also one of the few fields where an explicitly-inspired evolutionary thinking has some widely acknowledged lead in the methodology of empirical reseach, appreciative theories, and also formal models. And it also continues to be a major challenge for all those scholars who want to take micro-foundations seriously. As it stands now, it is probably a crucial test for any foundations of cognition, decision and learning -at least in economics,robust enough to account for what people and organisations do when they know inevitably little about what the future might deliver to them. In this respect, 'rational' formalisations sound sometimes helplessly silly ( ..suppose that stone-age men had rational expectations about helicopters, or more mundanely, that IBM's CEO's knew what a PC was and had whatever prior on their impact...).But, competing interpretations face the equally formidable challenge to develop "level zero" theories consistent with "higher level" models of the empirical patterns of learning in e.g. companies, or industries, communities, or whole countries ..

For the purposes of this work, let us just notice that a major step forward would come from constructive theories of entities that at higher levels of observations one calls "knowledge bases", "organisational competencies", "heuristics", etc. : that is, theories showing how elementary 'pieces of knowledge', or routines or elementary actions

${ }^{61}$ Whose collection, interestingly enough, has nearly stopped after the 60 's, as a result also of the conflict between what researchers were finding and the axiomatic boldness of the theory (cf. for example the neglect on mark-up findings with regards to pricing behaviours: a short but pertinent discussion is in Winter's chapter in Day and Graves (1975). 
coherently combine together in higher level entities that self-maintain over time. But in turn, as convincingly argued by Fontana and Buss (1994) and (1996) in the domain of biology, this demands a constructive theory of organisations ,whose existence, on the contrary, is most often postulated rather than explained ${ }^{62}$.

\section{(vi) Many open questions by way of a conclusion.}

It was one of the purposes of this paper to provide a broad map of diverse lines of inquiry, which, in different ways, take the analysis of cognition, action and learning beyond the boundaries of the canonical model of rational decision and rational learning. The underlying perspective - as we have tried to argue - is that a positive theory of agency in evolutionary environment will have to rely upon quite different building blocks as compared to the standard model.

Despite the length of this essay, we have been forced to leave out a few pertinent issues.

Let us conclude by flagging them out and suggest also some further research questions that we consider very high on the evolutionary research agenda.

\section{Learning and selection.}

Coupled with learning, the other major tenet of evolutionary theory is, of course, selection, that is some collective mechanism providing differential rewards and penalties

\footnotetext{
${ }^{62}$ In economics, principal/agent models as well as transaction cost theories of course try to do that. But , in the former case they do it by reducing them to a sort of epiphenomenological 'veil' , which is just a collective name for an ensemble of contracts among rational agents. Conversely, transaction cost models do fully acknowledge organisations as entities in their own right, but, in our view, they still fall short of providing a 'physiology' of organisation themselves, whereby governance procedures and problem-solving knowledge are reproduced and modified over time.

For remarks in a similar spirit, cf. Padgett(1995), who also present a simple 'hypercycle model' of emergence of an 'ecology' of mutually consistent skills.

See also Warglien (1995), on the evolution of organisational learning as a hierarchically nested process of selection among 'projects'.
} 
(involving also differential diffusion and survival probabilities) to different traits (being they behaviours, routines, technologies, etc...) of which the agents are so to speak "carriers",63.

More generally, we suggest almost all dynamics of socio-economic change fell somewhere in between the two extreme archetypes of "pure learning" and "pure selection". The former corresponds to the extremist decision-theoretic or game-theoretic models : all agents make the best use of the available information, are endowed with identical information-processing algorithms, etc. (representative-agent, rational expectation models are the most striking example). Clearly, here selection plays no role since every agent has the same access to the available opportunities (i.e. in some loose sense, has the same "environmental fitness"). Conversely, in the opposite "Darwinian" archetype, nobody learns and system dynamics is driven by selection operating upon blindly generated variants of e.g. behaviours, technologies, etc. (taken literally this is also the "as..if" interpretation of rational behaviour). As briefly discussed earlier, the outcomes of the two dynamics, for whatever given environment, are equivalent only in some rather special cases. In general, the balance and interaction between learning and selection matters in terms of both finitetime properties of the process and long-term outcomes.

An implication is also that the nature and intensity of selective mechanisms are not orthogonal to learning patterns. There might be subtle trade-offs here. Weak selective pressures most likely allow the persistence of "slack" and "inefficient" behaviours (no matter how "efficiency" is defined in a particular context). On the other hand, too strong selective pressure might hinder learning in so far as the latter involves trial-and-error processes, probably bound to be, on average. Failures.

It is a dilemma that J. March has phrased in terms of "exploitation vs. exploration" (March (1991)).

It can be seen also as a time-scale issue : learning and selection might well proceed at different paces. So for example, even the tightest selection environment can leave room for individual learning provided that selection is a low frequency event as compared to the rates of search/learning. In biology, selection takes place at a generational time scale. Hence the trade-off is very clear: individual learning is favoured by having long-living organisms, while collective evolution takes advantage of short-living organisms and frequent generational renewal. Conversely, in the social domain the picture is more complicated: environments such as markets are not only fundamental selection mechanisms, but also an essential source for feed-backs which stirs learning processes.

${ }^{63}$ General discussions of selection processes in socio-economic evolution can be found in Nelson and Winter (1882), Hodgson (1988), Dosi and Nelson (1995), Witt (1992), Metcalfe (1994), Nelson (1995), Silverberg (1988), Winter (1988), among others. 
Low frequency feed-backs can slow down and render "opaque" individual learning but a frequent and tight application of selective forces might leave little room for experimentation and innovation. Moreover, note that the cultural reproduction of knowledge and behaviours within economic institutions introduces strong "Lamarkian" features into the relationships between learning and selection.

Another, related, issue concerns the possible tension between individual and collective learning : for example, it might well happen that persistent individual mistakes (e.g. decision biases) turn out to have a positive collective role (an interpretation along these lines of the process of entry of business firms is in Dosi and Lovallo (1995) but a lot more needs to be done in order to explore the value of this conjecture).

\section{Learning, path-dependency and co-evolution.}

A quite general property of learning processes is often their path-dependent nature. This sometimes holds even under quite conventional learning mechanisms ${ }^{64}$ and even more so in evolutionary environments. Of course, path-dependency implies that initial conditions and/or early fluctuations along the learning path shape long term outcomes. Furthermore, if learning entails the development of rather inertial cognitive frames and routinised action rules, one should expect inertia and "lock-in" to be indeed one of the corollaries of the very fact that "agents have learned".

Above, we have surveyed a few models of e.g. technological learning, etc., which do generate path-dependency, lock-in, etc. even in rather simple environments, driven by some forms of dynamic increasing returns or social adaptation. A more complicated and fascinating question concerns those path-dependent outcomes which are driven by the correlation across (cognitive, behavioural, organisational) traits, which in biology comes under the heading of epistatic correlation (cf. Levinthal (1996a) for a suggestive exploratory

64 For example, this is true for Bayesian learning if the set of events upon which agents form their priors is different, and also in finite-time if agents hold the same priors but are exposed to different sample paths. And it appears as a limit property of environments where Bayesian agents sample across other bayesian agents in order to decide among alternative options (cf. Arthur and Lane (1993)). 
application to the analysis of organisational "inertia") ${ }^{65}$. The basic intuition is simple. Suppose that, say, cognitive and behavioural repertoires come as rather folded packages either due to some proximate internal coherence, or simply to the fact that originally they randomly happened to come together -. For example, in the above formal framework, suppose that the set of representations/actions which turned out to be "learned" involves the rule $r_{p}$ mapping an "understanding" of the world in terms of $\left(\vartheta_{1}, \vartheta_{2}, \ldots\right)$ into procedures $\left(\xi_{1}, \xi_{2}, \ldots.\right)$. Suppose also that that rule happened to "win" because in an environment with "true" states which are cognitively coded under $\vartheta_{\mathrm{i}}$, procedure $\xi_{\mathrm{i}}$ was reinforced by the obtained payoffs. However, under some other states , which, say, are coded in $\vartheta_{\mathrm{j}}$, triggering $\xi_{\mathrm{j}}$, , the decision rule is strikingly bad. Of course, with no trait correlation, agents would hold on, to that part of the original rule that links $\vartheta_{\mathrm{i}}$ to $\xi_{\mathrm{i}}$ and change the rest of the repertoire by merging it with e.g. representation $\vartheta_{\mathrm{k}}$ and intended action $\xi_{\mathrm{k}}$. However, suppose that the first "package" can be hardly unbundled, and so does the other one where, say $\vartheta_{\mathrm{k}} \xi_{\mathrm{k}}$ and come also correlated within another "model" yielding "bad" responses under the states coded under $\vartheta_{\mathrm{i}}$. One can intuitively see here how some system interrelatedness can easily produce inertia and lock-in (cf. David (1995), discussing also the appealing analogy between technological and institutional systems).

It is important to notice that interrelatedness and trait correlation are far from being theoretical curiosa. Rather, they are almost intrinsic properties of all entities embodying relatively coherent inner structures. This applies to knowledge systems, as well as business organisations and all other institutions. (A deeper understanding of this correlation draws back to the challenge of developing constructive theories of these entities themselves, mentioned earlier,...)

The ramifications of this point are even broader, linking with the idea of learning as a co-evolutionary process. It is quite straightforward from our earlier discussion that the general view of learning that we propose rests on the co-evolution between cognitive representations, behavioural repertoires and preferences. In a nutshell, this implies a notion of mutual adaptation, not only, of course, along the canonical sequence from what one believes to know to what one does, judged according to what one deems to be better for himself, but also the other way round, from what one does to what one has to believe in order to justify what has been done, and from what one gets to what one likes .

65 Kauffman's model of biological evolution is an acknowledged source of inspiration (Kauffman (1993)). 


\section{Preference and expectation.}

We have presented above some tentative insights toward the formalisation of the coevolution between mental models and action repertoires. Two other domains, however have been so far largely neglected, namely expectation formation and endogenous preferences. With regards to expectations, the rather unfortunate state-of-the-art is that one is largely stuck between a rational expectation paradigm which basically assumes agents who already know what they are supposed to learn and various extrapolative expectation mechanisms. Between the two, evolutionary modellers tend, rightly so, to choose the latter as a first approximation (cf. for example, Chiaramonte et al. (1993)), but, sooner or later, one should try to model agents that elaborate conjectures about the "structure of the world" and its parametrisation and test them against experience. More precisely, this is indeed what adaptive learning models do (e.g. Holland et al (1986), Marengo and Tordjman (1996), etc.), but the drawback is that one either has "pure forecast" models (whereby the triggered "action" is the forecast itself) or models where forecast and action-selection (concerning e.g. price-levels, selling-or buying, etc.) are folded together. A major step forward would be, in our view, the development of models whereby search in the space of expectations on the states-of-the-world and search in the space of actions is partly de-coupled ${ }^{66}$. A consequence would be also the possibility of handling the coexistence of partly conflicting systems of beliefs and action patterns ${ }^{67}$, and it would allow also an explicit account of phenomena like cognitive dissonance (Festinger (1957), Hirshman(1965) and Akerlof and Dickens (1972) for some economic applications) ${ }^{68}$.

This leads directly to the issue of endogenous preferences. Some progress has been recently made toward modelling preferences as influenced by social interactions (cf. e.g. Kuran (1987) and Brock and Durlauf (1995)). The time is possibly ripe to take the issue further, right into the foundational model of agency, and account for the endogeneity of the criteria by which representations, actions and "payoffs" are evaluated, certainly as a result of social imitation, but also driven by attempts to adjust "desires" to realised outcomes. (A

66 See a preliminary attempt in Riolo (1990).

67 Think for example of action patterns that continue to be implemented because they "work" even if they conflict with agent-held theories. Speculative behaviour involving both a rule "buy as long as the market is bullish" and expectation "the market is going to collapse" belong to this class (we owe this observation to H. Tordjman).

68 The fact that the belief system and the action system remain partly coupled, generally entails imperfect attempts to reduce cognitive dissonance by modifying also the system of beliefs in order to accommodate the action patterns. Every smoker, for example, is familiar with such exercises!! In a very similar vein, we plan to call a model of this kind, that we are beginning to build, "the spirit is strong, but the flesh is weak.."(!?) 
probably apocryphal citation of Joseph Stalin, mentions his definition of "pure happiness as the perfect correspondence between expectations and reality" (!!) : certainly he was trying hard to work on the former...). So far, these phenomena have been neglected by adaptive learning models : indeed, an aspect that we consider rather unsatisfactory is the general assumption of an invariant payoff function, which also drives the learning process, by providing the yardstick against which the outcomes of cognition/action are judged. Our proposal, on the contrary, in our earlier language, is to render the $\pi$ function endogenous -an implication being also that one disposes of any notion of "utility" as one of the primitives of the theory and operationalises on idea of adaptive identities of agents much nearer a lot of sociological intuitions.

\section{Co-evolutionary determinants of routines and other organisational traits.}

Isomorphic issues appear also at higher levels of description. Consider, for example, the co-evolution of technologies, business organisations and related institutions, raised in an appreciative theorising mode by Nelson (1994); or the multiple nature of routines as procedures for both problem-solving and governance of conflict (Coriat and Dosi (1995a)). In all these cases, organisational learning is driven by multiple, and possibly contradictory, selection mechanisms (for example, success in innovative search but also control over the possibility of opportunistic or conflictual behaviours, and political "coherence" of the organisation, etc.) ${ }^{69}$. On all that there is a wealth of empirical evidence and one starts having some appreciative theories : it might be worth beginning to explore also some simple formal models whereby organisational learning concerns the development of collectivelyshared cognitive models and action repertoires which, so to speak, "make sense" according to multiple dimensions (implying also that what members of the organisation "know", do and believe to be their interests, co-evolve.).

A major implication of all that is also that evolutionary theories of learning might head toward the hierarchically nested levels of description of learning processes ${ }^{70}$, possibly related to different learning entities. At one extreme, one is only beginning to explore the dynamics of, so to speak, "agentless" organisations where learning is driven by evolution under some selective pressure upon bundles of routines, skills, etc. (preliminary efforts are in Marengo (1996), Padgett (1995)). At the other extreme, it seems equally promising to

\footnotetext{
${ }^{69}$ A few more comments are in Dosi (1995a).

${ }^{70}$ An exploratory attempt is in Warglien (1995).
} 
explore explicit agent-based models where collective knowledge emerge from the endogenous networking among entities embodying diverse pieces of knowledge ${ }^{71}$.

Somewhere in between, as discussed at greater length in Coriat and Dosi (1995a), a major challenge ahead is modelling agents which imperfectly learn how to adapt (in terms of skills, behaviours, goals) to existing institutions while the imperfectness of adaptation itself is a fundamental source of institutional change ${ }^{72}$.

There is a lot on the plate. It seems to us that one faces nowadays the possibility of an interdisciplinary construction of a positive theory of agency and learning whose scope goes well beyond the limits of applicability of the usual (rational) decision-theoretic model. And, for the first time, one is beginning to develop the instruments to make it "harder" - able to generate also formal "toy models" that, moreover, have a positive interaction with models based on more orthodox notions of rationality. (Although, in our view, it will never be able to present the axiomatic "hardness" of the latter, notwithstanding its measure-zero empirical content, whenever stripped of any phenomenological restrictions).

As economists, we are tempted to call this emerging approach with the labels of "evolutionary" or "institutionalists". But, in other disciplines similar approaches come under quite different headings.

Moreover, even within the economists' arena, a few "revisionists" developments building on "bounded rationality", "far-from-equilibrium learning", etc. promise challenging dialogues. Nowadays, it is certainly far too early to know whether it will turn out to be scientifically more fruitful to pursue some equivalent of a "new Ptolemaic synthesis" or conversely, some more radical views, still largely to be developed. Where our inclinations are should be clear from this essay. In any case, whether one succeeds or not, it remains important to establish sort of equivalence classes, partly mapping problems and formal instruments across different approaches. This kind of bridge is also part of what we have tried to do in this paper. But, of course, it will never be long enough to reach rationality fanatics and drunk men who search for their lost house-key under some street light even if they know they forgot somewhere else....

\footnotetext{
${ }^{71}$ Which would indeed put on more rigorous grounds also the Hayekian proposition on capitalist institutions (including markets) as mechanisms for the coordination of distributed knowledge (cf. also Egidi (1996) and Lane et al. (1996)).

${ }^{72}$ One can easily see how this could represent also a major bridge between evolutionary theories and institutionalist analyses of the mechanism holding together and changing the social fabric (a thorough discussion of many related issues in Hodgson (1988)). Enormously difficult but fascinating issues
} 


\section{Bibliography}

Aghion P. and P. Howitt (1992), A model of growth through creative destruction, Econometrica, vol. 60 .

Akerlof G.A. and W.T. Dickens (1982), "The Economic Consequences of cognitive dissonance", American Economic Review, republished in Maital and Maital (1993).

Allen B. (1982a), A stochastic processes of interdependent demand and technological diffusion of an innovation exhibiting externalities among adopters, International Economic Review, vol. 23.

Allen B. (1982b), Some stochastic interactive model for the diffusion of information, Journal of Mathematical Sociology, vol. 8.

An M. and N. Kiefer (1993), Local externalities and societal adoption of technologies, Journal of Evolutionary Economics, vol. 5.

Anderlini L. and A. Ianni (1993), Path-dependence and learning from neighbours, mimeo.

Andersen E.S. (1994), Evolutionary Economics - Post Schumpeterian Contribution, London, Francis Pinter and New York, St. Martin's Press.

Aoki M. (1993), Aspects of conventions within the firm, Stanford University, mimeo.

Arifovic J. (1994), Genetic Algorithm Learning and the Cobweb Model, Journal of Economic Dynamics and Control, vol. 18, pp. 3-28.

Arrow K. (1962), Economic welfare and allocation of resources for invention, in N. Rosenberg (ed.), The Economics of Technological Change, Harnondsworth, Penguin.

Arrow K. (1974), The limit of organisation, New York and London, W. W. Norton and Co..

Arthur B.W. (1989), Increasing returns, competing technologies and lock-in by historical small events : the dynamics of allocation under increasing returns to scale, Economic Journal, vol. 99.

Arthur B.W. (1990), Silicon Valley locational clusters: when do increasing returns imply monopoly ?, Mathematical Social Sciences, vol. 19.

Arthur B.W. (1993), “On designing artificial agents that behave like human agents", Journal of Evolutionary Economics, 3, pp. 1-22

such as e.g. the dynamic coupling between institutions and economic behaviours; and the role of trust and power come under this broad headings. 
Arthur B.W., Yu. Ermoliev and Yu. Kaniovski (1984), Strong laws for a class of path-dependent stochastic processes with applications, in S. Argin and P. Shiryayev (eds.), Proceedings Conference on Stochastic Optimization, Berlin, Spriger Verlag, Lecture Notes in Control and Information Sciences.

Arthur B.W. and D. Lane (1993), Information Contagion, Structural Change and Economic Dynamics, vol. 4 ..

Axtell R. and J. Epstein (1994), Modelling artificial economies of adaptive agents, Laxenburg, Austria, IIASA Colloquium on Evolutionary Economics.

Bak P. et al. (1993), Aggregate flactuations from independent sectoral shocks: self-organized criticality in a model of production and inventory dynamics, Ricerche Economiche, vol. 47.

Bala V. and S. Goyal (1993), Learning from neighbours, mimeo.

Banerjee A.V. (1992), A simple model of herd behaviour, Quarterly Journal of Economics, vol. 107.

Barron J.N and M.T. Hannan (1994), The Impact of Economics on Contemporary Sociology, Journal of Economic Literature, vol. 32, pp. 1111-46.

Bateson G. (1972), Steps to an Ecology of Mind, New York, Ballantine Books

Berninghaus S.K. and U.G. Schwalbe (1992), Learning and adaptation processes in games with a local interaction structure, mimeo.

Berninghaus S.K. and U.G. Schwalbe (1996), Evolution, interaction and Nash equilibria, Journal of Economic Behavior and Organization, vol. 29.

Beyth-Marom R. (1990), "Mis/Understanding Diagnosticity : direction and magnitude of change”, in Borcherding et al. (1990)

Bikchandani S.K., Hirshleifer D. and I. Welch (1992), A theory of fads, fashion, custom and cultural change as informational cascade, Journal of Political Economy, vol. 100, pp 992-1026.

Binmore K. (1990), Essays on the Foundations of Game Theory, Oxford, Blackwell.

Blume L.E. (1993), The statistical mechanics of strategic interaction, Games and economic behavior, vol. 5 .

Blume L.E. (1995), The statistical mechanics of best-response strategy revision, Games-andEconomic-Behavior, vol. 11, pp. 111-45.

Blume, L. E and D. Easley, (1989), Wealth Dynamics and the Market Selection Hypothesis, Cornell University, mimeo.

Boles T.L. and D.M. Messick (1990), “Accepting Unfairness : temporal influences on choice”, in Borcherding et al. (1990) 
Borcherding K., D.L. Larichev and D.M. Messick (eds.) (1980), Contemporary Issues in Decision Making, Amsterdam/New York, Morta Holland

Bourdieu P. (1977), Outline of a Theory of Practice, Cambridge, Cambridge University Press

Brock W. And S. Durlauf (1995), Discrete Choices with Social Interactions I : Theory, Santa Fe, Santa Fe Institute WP 95-10-084

Bush R.R. and F. Mosteller (1955), Stochastic Models for Learning, New York, Wiley.

Camerer C.F. and E.J. Jonhson (1991), "The process-performance paradox in expert judgement: How can experts know so much and predict so badly?" in Ericsson and Smith (eds.).

Carlsson B. and G. Eliasson (1994), “The nature and importance of econoic competence”, Industrial and Corporate Change, vol. 3, pp. 687-711.

Casti, J.L (1992), Reality Rules, New York, John Wiley.

Chiaromonte F. and G. Dosi (1993), Heterogeneity, competition and macroeconomic dynamics, Structural Change and Economic Dynamics, vol. 4, pp. 39-63.

Chiaromonte F., Dosi G. and L. Orsenigo (1993), Inovative learning and institutions in the process of development : on the microfoundations of growth regimes, in $\mathrm{R}$ Thomson (ed.), Learning and Technological Change, London, Macmillan.

Cohen M. and P. Bacdayan (1994), “Organizational routines are stored as procedural memory: Evidence from a laboratory study, Organizational Science, 5, pp. 554-568.

Cohen M., R. Burkhart, G. Dosi, M. Egidi, L. Marengo, M. Warglien, S. Winter, and Coriat B. (1995), Routines and other recurring action patterns of organisations : Contemporary Research Issues, Santa Fe, Santa Fe Institute, Working Papers, forthcoming on Industrial and Corporate Change.

Cohen, M.D., J.G. March and J.P. Olsen (1972), A Garbage Can Model of Organizational Choice, Administrative Sciences Quarterly, vol. 17.

Conlisk J. (1989), An aggregate model of technical change, Quarterly Journal of Economics, vol. 104.

Coriat B. and G. Dosi (1995a), Learning how to govern and learning how to solve problems : On the co-evolution of competences, conflicts and organizational routines, Laxenburg, Austria, IIASA WP 95-06.

Coriat B. and G. Dosi (1995b), The insitututional embeddedness of economic change. An appraisal of the "Evolutionary" and "Regulationist" Research Programmes, IIASA, Laxenburg, Austria, Working Paper WP 95-117

Cyert R.M. and J.G. March (1963), Behavioral Theory of the Firm, Englewood Cliffs, Prentice Hall. 
Dalle, J.M. (1993), Dynamiques d'adoption, coordination et diversité : le cas des standard technologiques, Paris, IEPE, mimeo.

Dalle, J.M. (1994a), Decision autonomes et coexistence des technologies, Paris, IEPE, WP 9401.

Dalle, J.M. (1994b), Technological competition, micro-decisions and diversity, Paris, IEPE, mimeo.

David P.A. (1975), Technical Choice, Innovation and Economic Growth, Cambridge University Press.

David P.A. (1985), Clio and Economic of QWERTY, American Economic Review, 75, pp.332-337.

David P.A. (1990), The Dynamo and the Computer: An Historical Perspective on the Modern Productivity Paradox, American Economic Review, vol. 80, pp. 355-61.

David P.A. (1993), Path-dependence and predictability in dynamic systems with local externalities : a paradigm for historical economics", in D. Foray and Ch. Freeman (eds.), Technology and the Wealth of Nations, London, Pinter.

David P.A. (1995), Institutions as the carriers of history, Structural Change and Economic Dynamics, vol. 6 .

David P.A. and D. Foray (1992), Markov random fields, percolation structures and the economics of EDI standard diffusion, Stanford, CEPR Discussion Paper 326.

Davidson D. and P. Suppes (1977), Decision Making : An experimental approach, Westport Conn., Greenwood.

Day R.H. and P. Chen (eds.) (1993), Non linear and evolutionary economics, Cambridge, Cambridge University Press

Day R.H. and T. Groves (eds.) (1975), Adaptive Economic Models, New York, Academic Press.

Dosi G. (1984), Technical Change and Industrial Transfromation. The Theory and an Application to the Semiconductor Industry, London McMillan.

Dosi G. (1988), "Sources, procedures and microeconomic effects of innovation", Journal of Economic Literature.

Dosi G. (1995a), Hierarchies, markets and power: some foundational issues on the nature of comtemporary economic organizations, Industrial and Corporate Change, vol. 4, pp. 1-19.

Dosi G. (1995b), The contribution of economic theory to the understanding of a knowledge based economy, IIASA WP 95-56.

Dosi G. and M. Egidi (1991), Substantive and procedural uncertainty. An exploration on economic behaviours in changing environments", Journal of Evolutionary Economics, vol. 1, pp. 145168. 
Dosi G., C. Freeman, R. Nelson, G. Silverberg and L. Soete (eds.) (1988), Technical Change and economic Theory, London, F. Pinter and New York, Columbia University Press.

Dosi G. and Yu. Kaniovski (1994), On 'badly behaved' dynamics, Journal of Evolutionary Economics, vol. 4.

Dosi G. and D. Lovallo (1995), "Rational Entrepreneurs or optimistic Martyrs ? Some considerations on Technological regimes, corporate Entries and the evolutionary Role of Decision Biases", Laxenburg, Austria, IIASA, WP 95-77, forthcoming in R. Garud et al. (1996).

Dosi G. and F. Malerba (1996), Organization and Strategy in the Evolution of the Enterprise, London, MacMillan.

Dosi G. and L. Marengo (1994), “Toward a Theory of Organizational Competencies”, in R.W. England (ed.), Evolutionary Concepts in Contemporary Economics, Ann Arbor, Michigan University Press, pp. 157-178.

Dosi G., L. Marengo, A. Bassanini and M. Valente (1994), Norms as emergent properties of adaptive learning. The case of economic routines, IIASA, Laxenburg, Austria Working Paper WP 9473

Dosi G., O. Marsili, L. Orsenigo and R. Salvatore (1995), Learning, market selection and the evolution of industrial structure, Small Business Ecoonmics.

Dosi G. and S. Metcalfe (1991), "On some notions of irreversibility in economics”, in P. Saviotti and S. Metcalfe (1991).

Dosi G. and R. Nelson (1994), “An introduction to evolutionary theories in economics”, Journal of Evolutionary Economics, 4, pp. 153-172

Dubois D. and H. Prade (1988), Modelling Uncertainty and Inductive Inference : A Survey of Recent Non-Additive Probability Systems, Acta Psychologica, vol. 68, pp. 53-78.

Durlauf S.N. (1994), Path-dependence in aggregate output, Industrial and Corporate Change, vol. 3.

Easley D. and A. Rustichini (1995), Choice without beliefs, CORE, Catholic University of Louvain, Louvain-la-Neuve, Working Paper

Edgerton R.B. (1985), Rules, Exceptions and Social Order, Berkeley and Los Angeles, University of California Press

Egidi M. ( 1996) "Routines, hierarchies of problems , procedural behaviour : some evidence from experiments", forthcoming in K. Arrow et al. (eds.) The Rational Foundations of Economic Behaviour, London, MacMillan, pp. 303-333

Einhorn H.J. and R.M. Hogart (1985), “Ambiguity and Uncertainty in Probabilistic Inference”, Psychological review, 86, pp. 433-461 
Eliasson G. (1985) The firm and financial markets in the Swedish micro-to-macro model, Stockholm, IUI.

Elster J. (ed.) (1986), The multiple self, Cambridge, Cambridge University Press.

Ericsson K.A. and J. Smith (eds.) (1991), Toward a General Theory of Expertise, Cambridge/New York, Cambridge University Press

Estes W.K. (1950), “Toward a statistical theory of learning”, Psychological Review, 57, pp. 94-107.

Feldman M. (1991), On the generic nonconvergence of Bayesian actions and beliefs, Economic Theory, vol. 1.

Festinger L. (1957), A theory of cognitive dissonance, Stanford, Stanford University Press

Fisher F.M. (1985), Disequilibrium Foundations of Equilibrium Economics, Cambridge, Cambridge University Press.

Fisher R.A. (1930), The Genetical Theory of Natural Selection, Oxford, Oxford University Press.

Föllmer H. (1973), Random economies with many interacting agents, Journal of Mathematical Economics, vol. 1.

Fontana W. And L. Buss (1994) The arrival of the fittest : Toward a theory of biological organization, Bulletin of Mathematical Biology, 56, pp. 1-64.

Fontana W. And L. Buss (1996), The barrier of Objects : from Dynamical Systems to Bounded Organizations, Laxenburg, Austria, IIASA WP 96-27.

Foray D. and B.A. Lundvall (eds.) (1996), Knowledge, Employment and Economic Growth, Paris, OECD, forthcoming.

Foster D. and P.H. Young (1990), Stochastic evolutionary game dynamics, Theoretical Population Biology, vol. 38 .

Freeman Ch. (1982), The Economics of Industrial Innovation, London, Pinter, $2^{\text {nd }}$ ed..

Freeman Ch. (1994), The Economics of Technological Change, Cambridge Journal of Economics.

Friedman D. (1991), Evolutionary games in economics, Econometrica, vol. 59, pp. 637-66.

Friedman M. (1953), Essay in Positive Economics, Chicago, University of Chicago Press.

Fudenberg D. and C. Harris (1992), Evolutionary dynamics with aggregate shocks, Journal of Economic Theory, vol. 57.

Fudenberg D. and D.M. Kreps (1993), Learning mixed equilibria, Games and Economic Behavior, vol. 5 . 
Fudenberg D. and D.K. Levine (1995), Consistency and Cautious Fictitious Play, Journal of Economic Dynamics and Control, vol. 19, pp. 1065-89.

Garud R., P. Nayyar and Z. Shapira (eds.) (1996), Technological Foresights and Oversights, Cambridge/New York, Cambridge University Press.

Geertz C. (1963), Peddlars and Princes, Chicago, Chicago University Press

Glaziev S. and Yu. Kaniovski (1991), Diffusion of innovations under conditions of uncertainty : a stochastic approach, in N. Nakicenovic and A. Grubler (eds.), Diffusion of Technologies and Social Behaviour, Berlin, Springer Verlag.

Goffman E. (1974), Frame Analysis. An essay on the organisation of experience, Harmondsworth, Penguin

Gould S.J. (1977), Ontogeny and Phylogeny, Cambridge Mass., Harvard University Press.

Gould S.J. and R.C. Lewontin (1979), “The spandrels of San Marco and the Panglossian paradigm : a critique of the adaptionist programme", Proceedings of the Royal Society, London, 205, pp. 581-598.

Granovetter M. (1985), "Economic Action and Social Structure : the Problem of embeddedness", American Journal of Sociology, 91, pp. 481-510

Granstrand O. (1994a), “Technological, technical and economic dynamics” in O. Granstrand (1994b).

Granstrand O. (ed.) (1994b), Economics of Technology, Amsterdam, North-Holland.

Griffin D. and A. Tversky (1992), "The weight of evidence and the determinants of confidence", Cognitive Psychology, 24, pp. 411-435.

Grimmett G. (1989), Percolation, Berlin, Springer Verlag.

Grossman G.M. and E. Helpman (1981), Innovation and Growth in the Global Economy, Cambridge Mass., MIT Press.

Hammersley J.M. and D.J. Welsh (1980), Percolation theory and its ramifications, Contemporary Physics, vol. 21.

Hanusch H. (ed.) (1988), Evolutionary Economics. Applications of Schumpeter's Ideas, Cambridge, Cambridge University Press

Heath C. and A. Tversky (1990), "Preference and belief : Ambuiguity and Competence in Choice under Uncertainty", in Borcherding et al. (1990)

Heiner R.A. (1983), The origin of predictable behavior, American Economic Review, vol. 73, pp. 560-595. 
Herrnstein R.J. (1991), Experiments on stable suboptimality in individual behavior, Santa Fe, Santa Fe Institute WP 91-02-015.

Herrnstein R.J., G. Lindrey and R.D. Luce (eds.) (1989), Steven's Handbook of Experimental Psychology, $2^{\text {nd }}$ ed., Chichester/New York, Wiley

Herrnstein R.J. and Prelec (1991), "Melioration: A theory of distributed choice", Journal of Economic Perspectives, vol. 5, pp.137-56.

Herz A.V. (1994), Collective phenomena in spatially extended evolutionary games, Journal of Theoretical Biology, vol. 169.

Hicks D. (1995), Published papers, tacit competencies and corporate management of the public/private character of knowledge, Industrial nad Corporate Change, vol. 4, pp. 401-424.

Hirschleifer D. (1993), The blind leading the blind: social influence, fads and informational cascades, Los Angeles, Anderson Graduate School of Management, UCLA, WP 24-93.

Hirschman A. (1965), "Obstacles to development: A classification and a quasi-vanishing act", Economic Development and Cultural Change, 13, pp. 385-93.

Hirschman A. (1977), The Passion and the Interest, Princeton NJ, Princeton University Press.

Hodgson G.M. (1988), Economics and Institutions: A Manifesto for a Modern Institutional Economics, Cambridge, U.K., Polity Press.

Hodgson G.M. (1993), Economics and Evolution, Cambridge, Polity Press

Hoffmeister, F. and M. Bäck (1991), Genetic Algorithms and Evolution Strategies - Similarities and Differences, Papers on Economics and Evolution No. 9103, edited by the European Study Group for Evolutionary Economics.

Holland J.H., K.J. Holyoak, R.E. Nisbett and Thagard (1986), Induction, Cambridge, Mass., MIT Press

Hors I. and F. Lordon (1994), Des modèles de transition de phase en économie, Paris, CEPREMAP, mimeo.

Huberman B. and T Hogg (1995), Distributed computation as an economic system, Journal of Economic Perspectives, 9, pp. 141-52.

Ioannides Y.M. (1990), Trading uncertainty and market form, International Economic Review, vol. 31.

Ivan Schic E.C.M. and J. Van del Pligt (1990), "Influence diagrams and fault Trees : the role of salience and anchoring", in Borcherding et al. (1990)

Johnson-Laird P. (1983), Mental Models, Cambridge, Mass., Harvard University Press 
Johnson-Laird P. (1993), The computer and the mind, London, Fontana Press, $2^{\text {nd }}$ ed.

Kahneman D., J. Kanetch and R. Thaler (1990), "Experiment tests of the endowment effect and the Coase theorem", Journal of Political Economy, 98, pp. 325-48.

Kahneman D. and D. Lovallo (1993), “Timid Choice and Bold Forecast : A cognitive perspective on risktaking”, Management Science, vol. 39.

Kahneman D., P. Slovic and A. Tversky (eds.) (1982), Judgment under uncertainty. Heuristics and Biases, Cambridge, Cambridge University Press.

Kahneman D. and A. Tversky (1986), "Rational Choice and the Framing of Decision”, Journal of Business, 59, pp. 251-278

Kalai E. and E. Lehrer (1993), Rational learning leads to Nash equilibrium, Econometrica, vol. 61.

Kalai E. and E. Lehrer (1994), Weak and strong merging of opinions, Journal of Mathematical Economics, vol. 23.

Kandori M., G.J. Mailath and R. Rob (1993), Learning, mutation and long run equilibria in games, Econometrica, vol. 61.

Kaniovski Yu., and P. H. Young (1994), Learning dynamics in games with stochastic perturbations, Games and Economic Behavior, vol. 11, pp. 330-363.

Kaniovski Yu., A.V. Kryazhimskii and P. H. Young (1994), On the robustness of stochastic best reply dynamics in repeated games, Laxenburg, Austria, IIASA, WP 96-45

Katona G. (1951), Psychological Analysis of Economic Behaviour, New York, McGraw-Hill.

Katona G. (1968) "Behavioral and Ecological Economics, Consumer behaviour : theory and findings on expectations and aspirations", American Economic Review, vol. 58, republished in Maital and Maital (1993).

Kauffman, S. (1993), The Origins of Order, Oxford, Oxford University Press.

Kindermann R. and J.L. Snell (1980), Markov random fields and theirapplications, American Mathematical Society, vol. 1.

Kirman A.P. (1992), Variety : the coexistence of techniques, Revue d'Economie Industrielle, vol. 59.

Kirman A.P. (1993), Ants, rationality and recruitment, Quarterly Journal of Economics, vol. 108, pp. 137-56.

Kirman A.P. (1994), Economies with interactiong agents, mimeo.

Kirman A.P., Oddou C. and S. Weber (1986), Stochastic communication and coalition formation, Econometrica, vol. 54. 
Kirman A.P. and M. Salmon (eds.) (1995), Learning and Rationality in Economics, Oxford, Basil Blackwell.

Kogut B. (ed.) (1993), Country competitiveness : Technology and the organizing of work, Oxford, Oxford University Press.

Koutsougeras L. and N.C. Yannelis (1994), Convergence and approximation results for noncooperative Bayesian games : learning theorems, Economic Theory, vol. 4.

Koza J. (1993), Genetic Programming, Cambridge Mass., MIT Press.

Kreps D.M. (1996), "Market and Hierarchies and (Mathematical) Economic Theory", Industrial and Corporate Change, forthcoming

Kuran T. (1987), "Preference falsification, policy continuity and collective conservatism", Economic Journal, vol. 97, pp. 642-655.

Kurz M. (1994a), On rational belief equilibria, Economic Theory, vol. 4.

Kurz M. (1994b), On the structure and diversity of rational beliefs, Economic Theory, vol. 4.

Kwasnicki W. (1996), Knowledge, Innovation and Economy, Cheltenham, Edward Elgar.

Lakoff G. (1987), Women, fire and dangerous things. What categories reveal obout the mind, Chicago, University of Chicago Press

Lane D. (1993a), Artificial worlds in economics : Part I, Journal of Evolutionary Economics, vol. 3. Pp. 89-107.

Lane D. (1993b), Artificial worlds in economics : Part II, Journal of Evolutionary Economics, vol. 3, pp. 177-197.

Lane D., F. Malerba, R. Maxfield and L. Orsenigo (1996), “Choice and Action”, Journal of Evolutionary Economics, vol. 6, pp. 43-75.

Lane D. and R. Vescovini (1996), Decision rules and market share : aggregation in an information contagion model, Industrial and Corporate Change, vol. 5, pp. 127-46.

Langlois, R.N. (1990), "Bounded rationality and behaviourism: A classification and a critique", Journal of Institutional and Theoretical Economics, 146, pp. 691-95.

Langlois R.N. and P.L. Robertson (1995), Firms, markets and economic change : A dynamic theory of business institutions, London, Routledge.

Langton Ch. G. (ed.) (1989), Articial Life, Redwood City Ca., Addison Wesley.

Langton Ch. G. et al. (eds.) (1991), Artificial Life II, Redwood City Ca., Addison Wesley.

Leibenstein H. (1950), "Bandwagon, Snob and Veblen Effects in the theory of Consumer Demand", Quarterly Journal of Economics, vol. 65, republished in Maital and Maital (1993) 
Lesourne, J., (1991), Economie de l'ordre et du désordre, Paris, Economica.

Levinthal D. (1996a), “Adaptation in rugged landscapes”, Management Science, forthcoming.

Levinthal D. (1996b), Surviving in Schupeterian evironments, in Dosi and Malerba (1996).

Lewis A. (1985a), On Effectively Computable Realization of Choice Funtions, Mathematical Social Sciences, vol. 10, pp. 43-80.

Lewis A. (1985b), The minimum degree of recursively representable choice funtions, Mathematical Social Sciences, vol. 10, pp. 179-88.

Lewis A. (1986), Structure and Complexity. The Use of Recursion Theory in the Foundations of Neoclassical Mathematical Economics and the Theory of Games, Ithaca, Cornell University, dept. Of Mathematics, mimeo.

Lindgren K. (1991), "Evolutionary phenomena in simple dynamics”, in Langton (1991).

Lorenz E. (1994), Organizational inertia and competitive decline : The British cotton, shipbuilding and car industries, Industrial and Corporate Change, vol. 3, pp. 405-34.

Lovallo D. (1996), From individual biases to organizational errors, in Dosi and Malerba (1996).

Lucas R.E. (1986), Adaptive behavior and economic theory, Journal of Business, vol. 59, pp. S40126.

Lundvall B.A. (ed.) (1995), National Systems of Innovation : Towards a Theory of Innovation and Interactive Learning, London, Francis Pinter.

Lundvall B.A. (1996), The social Dimension of the Learning Economy, Aalborg, DRUID WP 96-01.

Luria A.R. (1976), Cognitive development. Its cultural and social foundations, Cambridge, Mass., Harvard University Press

Maital S. and S.L. Maital (eds.) (1993), Economics and Psychology, Aldershot, Edward Elgar.

Malerba F. and L. Orsenigo (1996), The dynamics and evolution of industries, Industrial and Corporate Change, vol. 5, pp. 51-87.

March J.G. (1988a), "Variable risk preference and adaptive aspirations", Journal of Economic Behaviour and Organisation, 9, pp. 5-24

March J.G. (1988b), Decision and organisations, Oxford, Basil Blackwell

March J.G. (1991), “'Exploration and Exploitation in Organizational Learning”, Organization Science, vol. 2 : pp. 71-87.

March J.G. (1994), A Primer on Decision Making. How decisions happen, New York, Free Press

March J.G. and H.A. Simon (1958), Organizations, New York, Basil Blackwell. 
March J.G. et al. (1991), Learning from samples of one or fewer, mimeo.

Marengo L. (1996), "Structure, competences and learning in an adaptive model of the firm”, in G. Dosi and F. Malerba (1996),

Marengo L. and H. Tordjman (1996), "Speculation, heterogeneity and learning: A model of exchange rate dynamics", Kyklos, vol. 47.

Margolis H. (1987), Patterns, thinking and cognition, Chicago, University of Chicago Press

Marimon R. (1995), Learning from learning in economics (Towards a theory of the learnable in economics), Florence, European University Institute, Working Paper

Marimon R., E. McGrattan and Th. J. Sargent, (1990), Money as a Medium of Exchange in an Economy with Artificially Intelligent Agents, Journal of Economic Dynamics and Control, vol. 14 , pp. 329-73.

Mayer R.E. (1992), Thinking, problem solving, cognition, New York, W.H. Freeman, and ed.

Maynard-Smith J. (1982), Evolution and theory of games, Cambridge, Cambridge University Press.

Metcalfe, J.S. (1994), Evolutionary economics and technology policy, Economic Journal, vol. 104, pp. 931-44.

Metcalfe, J.S. (1996), Technology strategy in an evolutionary world, PREST, University of Manchester, working paper.

Milgram S. (1974), Obedience to authority : An experimental view, London, Tevistock Institute

Milgrom P. and J. Roberts (1991), Adaptive and sophisticated learning in normal form games, Games and Economic Behavior, vol. 3.

Montgomery C.A. (ed) (1995), Resource-Based and Evolutionary Theories of the Firm, Boston/Dordrecht/London, Kluwer.

Nelson R.R. (1987), Understanding technical change as an evolutionary process, Professor Dr. F. de Vries Lectures in Economics, vol. 8 Theory, Institutions, Policy, Amsterdam, North Holland.

Nelson R.R. (ed.) (1993), National Innovation Systems : A comparative study, Oxford, Oxford University Press.

Nelson R.R. (1994), The co-evolution of technology, industrial structure and supporting institutions, Industrial and Corporate Change, vol. 3, pp. 47-63.

Nelson R.R. (1995), Recent Evolutionary Thorizing About Economic Change, Journal of Economic Literature, vol. 33, pp. 48-90.

Nelson R. and S.G. Winter (1982), An Evolutionary Theory of economic change, Cambridge, Mass., The Belknap Press of Harvard University Press 
Newell A. and H.A. Simon (1972), Human Problem Solving, Englewood Cliffs, Prentice Hall.

Nowak M.A. and R.M. May (1992), Evolutionary games and chaos, Nature, vol. 359.

Nowak M.A. and R.M. May (1993), The spatial dilemmas of evolution, International Journal of Bifurcation and Chaos, vol. 3.

Nyarko Y. (1994), Bayesian learning leads to correlated equilibria in normal form games, Economic Theory, vol. 4.

Orléan A. (1990), Le rôle des influences interpersonnelles dans la détermination des cours boursiers, Revue Economiques, vol. 41, pp. 839-68.

Orléan A. (1992), Contagion des opinions et fonctionnement des marchés financiers, Revue Economiques, Vol. 43, pp. 685-97.

Orléan A. (1994), Analyse Economique des Conventions, Paris, Presse Universitaire de France.

Padgett J.F. (1995), “The emergence of simple ecologies of skills : a hypercycle approach to economic organization", forthcoming in B. Arthur, S. Durlauf and D. Lane (eds.), The Economy as a Complex Evolving System II, New York, Wiley.

Palmer, R.G., W.B. Arthur, J.H. Holland, B. LeBaron and P. Tayler (1994), Artificial Economic Life : A simple Model of a Stockmarket, Physica D, vol. 75, pp. 264-74.

Pascale R.T. (1984), “Perspectives on strategy : The real story behind Honda's success”, California Management Review, 26, pp. 47-71.

Pavitt K. (1982), The Objective of Technology Policy, Science and Public Policy, 14, pp.182-188.

Pavitt K. (1984), Sectoral patterns of technical change : towards a taxonomy and a theory, Research Policy, vol. 13, pp. 343-73.

Pearl J. (1984), Heuristics, Reading, Mass. Addison-Wesley.

Polanyi K. (1944), The Great Transformation, Boston, Beacon Press.

Polanyi K. (ed.) (1957), Trade and Market in the Early Empires, Glencoe, Ill., Free Press.

Posch M. (1994), Cycling with a Generalized Urn Scheme and a Learning Algorithm for 2 X2 Games, Laxenburg, Austria, IIASA WP 94-076.

Prahalad, C.K. and G. Hamel (1990), "The core competence of the corporation", Harvard Business Review, 68, n. 3, pp.79-91.

Purkitt H.E. and J.W. Dyson (1990), "Decision making under varying situational constraints", in Borcherding et al. (1990).

Riolo R.L. (1990), Lookahead planning and latent learning in a classifier system, University of Michigan, mimeo. 
Rip A., Misa T.J. and Schot J. (eds.) (1995), Managing Technology in Society. The Approach of Constructive Technology Assessment, London, Pinter.

Romer P. (1990), Endogenous technological change, Journal of Political Economics, vol. 98.

Rosenberg, N. (1976), Perspectives on Technology, Cambridge, Cambridge University Press

Rosenberg, N. (1982), Inside the Black Box, Cambridge, Cambridge University Press

Rosenberg N. (1994), Exploring the Black Box: Technology, Economics and History, Cambridge, Cambridge University Press.

Rustichini A. (1995), “Post-Bayesian Economics”, CORE, Catholic University of Louvain, Louvainla-Neuve, Working Paper.

Sargent T.J. (1993), Bounded Rationality in Economics, Oxford, Claredon Press of Oxford University Press .

Savage L. (1954), The Foundations of Statistics, New York, Wiley

Saviotti P. and S. Metcalfe (eds.) (1991) , Evolutionary theories of economic and technological change : present status and future prospects, Chur, Harwood Academic.

Scharfstein D.S. and J.C. Stein (1990), Herd behavior and investment, American Economic Review, vol. 80 .

Schnaars S.P. and C. Berenson (1986), Growth market forecasting revisited : A look back and a look forward, California Managemnt Review, vol. 28, pp. 71-87.

Selten R. (1989), Evolution, learning and economic behaviour, Games and Economic Behaviour, 3, pp. 3-24.

Sen A. (1982), Choice, welfare and measurement, Oxford, Blackwell.

Sen A. (1995), Maximizing bahaviours and the choice act, Fritch Memorial Lecture, World Econometric Congress, Tokyo.

Shackle G.L.S. (1969), Decision, Order and Time in Human Affairs, $2^{\text {nd }}$ ed., Cambridge University Press.

Sharif E.B., D.N. Osherson and E.E. Smith (1990), "Comparative Choice and the Advantage Model”, in Borcherding et al. (1990).

Sharif E.B. and A. Tversky (1992), “Thinking Through Uncertainty : Unconsequential Reasoning and Choice", Cognitive Psychology, 24, pp. 449-474

Silverberg G. (1988), Modelling economic dynamics and technical change: mathematical approaches to self-organization and evolution, in Dosi et al. (1988). 
Silverberg G., G. Dosi and L. Orsenigo (1988), Innovation, diversity and diffusion. A selforganization model, Economic Journal, vol. 98.

Silverberg G. and D. Lenhert (1994), Growth fluctuation in an evolutionary model of creative destruction, in G. Silverberg and L. Soete (eds.), The Economics of Growth and Technical Change, Aldershot, Edward Elgar.

Silverberg G. and B. Verspagen (1994), Learning, innovation and economic growth: a long run model of industrial dynamics, Industrial and Corporate Change, vol. 3, pp. 199-223.

Silverberg G. and B. Verspagen (1995a), Evolutionary theorizing on economic growth, Laxenburg, Austria, IIASA WP 95-78.

Silverberg G. and B. Verspagen (1995b), From the artificial to the endogenous: Modelling evolutionary adaptation and economic growth, Laxenburg, Austria, IIASA WP 95-08.

Simon H.A. (1965), Administrative Behaviour, New York, Free Press, $2^{\text {nd }}$ ed.

Simon H.A. (1976), "From substantive to procedural rationality", in S.J. Latsis (ed.), Method and Appraisal in Economics, Cambridge, Cambridge University Press.

Simon H.A. (1981), The Sciences of the Artificial, Cambridge, Mass., MIT, Press

Simon H.A. (1986), Rationality in Psychology and Economics, in R.M. Hogart and M.W. Reder, Rational Choice. The Contrast between Economics and Psychology, Chicago, University of Chicago Press.

Simon H.A. (1988), Models of thought. Vol. I, New Haven, Yale University Press, $2^{\text {nd }}$ ed.

Slovic P., S. Lichtenstein and B. Fischerhof (1989), "Decision Making” in Herrnstein et. al. (1989)

Smelser N.J. and R. Swedberg (eds.) (1994), The Handbook of Economic Sociology, Princeton, Princeton University Press.

Starbuck W.H. (1993), "Strategizing in the real world", Interantional Journal of Technology Management, 8, pp. 77-85.

Sterman J.D. (1989a), “Modeling Managerial Behaviour: Misperceptions of Feedback in a Dynamic Decision Making Experiment”, Management Science, 35, pp.321-338.

Sterman J.D. (1989b), "Deterministic Chaos in an Experimental Economic System", Journal of Economic Behaviour and Organization, 12, pp.1-28

Stoneman P. (ed.) (1995), Handbook of the Economics of Innovation and Technological Change, Oxford, Blackwell.

Suppes P. (1995a), A survey of mathematical learning theory 1950-1995, Stanford University, mimeo. 
Suppes P. (1995b), Learning by doing, or practice makes perfect, Stanford University, mimeo.

Svenson O. (1989), "Some propositions for the classification of decision situations", in Borcherding et al. (1990).

Teece D. and G. Pisano (1994), The dynamic capabilities of firms : An introduction, Industrial and Corporate Change, vol. 3, pp. 537-555.

Thaler R.H. (1992), The Winner's Curse : paradoxes and anomalies of economic life, New York, Free Press.

Topol R. (1991), Bubbles and volatility of stock prices: effects of mimetic contagion, Economic Journal, vol. 101.

Tordjman H. (1996), The formation of beliefs on financial markets: representativeness and prototypes, Laxenburg, Austria, IIASA, Working Paper.

Tversky A. and D. Kahneman (1982), "Judgments of and by representativeness", in Kahneman et al. (1982).

Vassilakis S. (1995), Accelerating new product development by overcoming complexity contraints, Florence, European University Institute, Working Paper

Verspagen B. (1993), Uneven growth between interdependent economies: A evolutionary view on technology gaps, trade and growth, Aldershot, Ashgate.

Vincenti, W.G. (1990), What engineers know and how they know it, Baltimore, John Hopkins University Press.

Vriend N. (1996), Self-organized markets in a decentralized economy, Journal of Computational Economics, forthcoming.

Warglien M (1995), Hierarchical selection and organizational adaptation, Industrial and Corporate Change, vol. 4, pp. 161-185.

Weibull J.W. (1995), Evolutionary Game Theory, Cambridge Mass., MIT Press.

Weidlich W. and G. Haag (1983), Cocepts and Models of Quantitative Sociology, Berlin, Springer Verlag.

Winter S.G. (1971), "Satisficing, selection and the innovative remnant", Quarterly Journal of Economics, 85, pp. 237-61

Winter S.G. (1986), Comments on Arrow and on Lucas, Journal of Business, vol. 59, pp. 5427-34.

Winter S.G. (1987), "Knowledge and Competence of Strategic Assets", in D.J. Teece, The Competitive Challange, Cambridge MA, Ballinger. 
Winter S.G. (1988), Economic "Natural Selection" and the Theory of the Firm, in P.E. Earl (ed.) Behavioural economics. Volume 1, Aldershot, Elgar.

Witt U. (ed.) (1992), Explaining process and Change : Approaches to Evolutionary Economics, Ann Arbor, Michigan University Press

Young P.H. (1993), The evolution of conventions, Econometrica, vol. 61. 